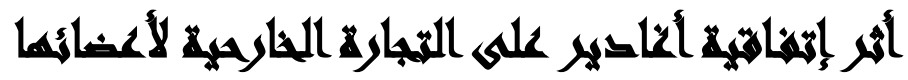

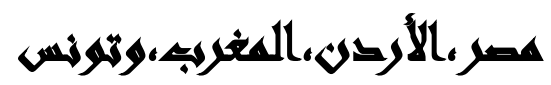

$[10]$

\author{
أحمد فؤاد مندور(')- ناجا عبد الحميد عبد العظيم أبو النيل(r)

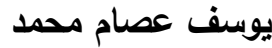

( ) كلية تجارة، جامعة عين شمس r) كلية الآداب، جامعة عين شمس مدمل

\section{الأمَستخلس}

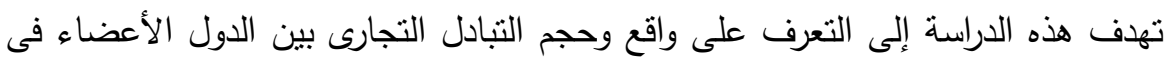

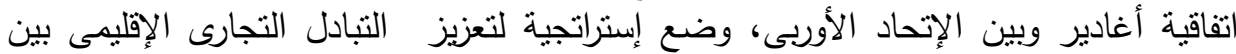

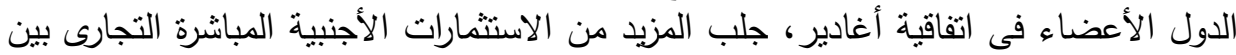

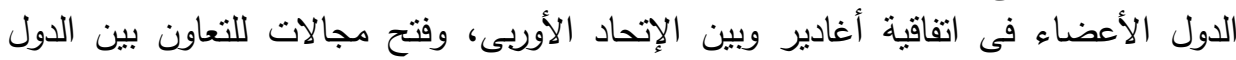

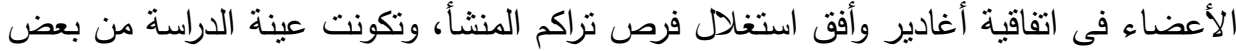
الدول الأعضاء فى اتفاقية أغادير وهى (مصر، الاردن، المغرب، تونس)، واستخدم الباحثّن

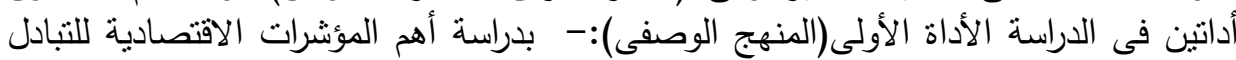
التجارى مع دول إتفاقية أغادير وكيفية تتمية التبادل التجارى لزيادة الاستثمارات الأجنبية

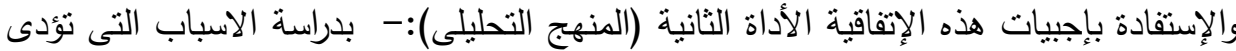

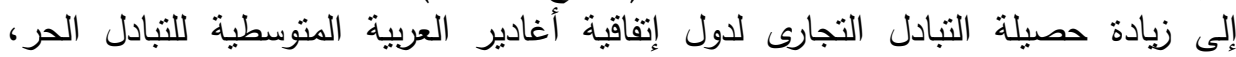

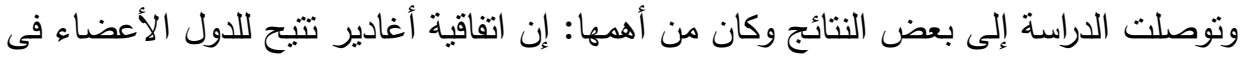
اتفاقية فرصة الحصول على المنح والمعونات والخبرات، التي يقدمها الجانب الأوروبي لتأهيل

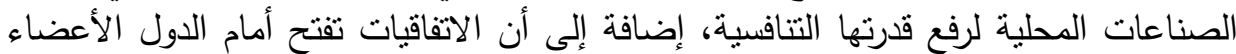

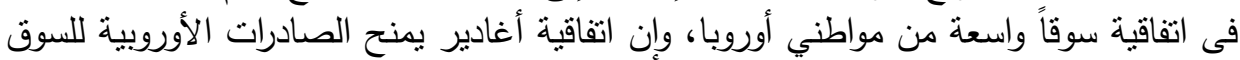
العربية مزايا واعفاءات جمركية تضاف إلى ما تملكه بالفعل من قدرات نتافسية عالية، وأيضا

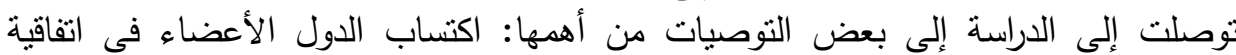

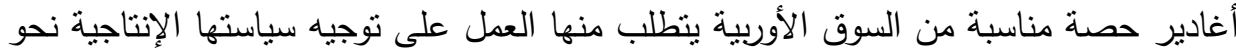

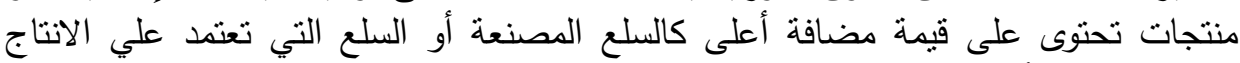

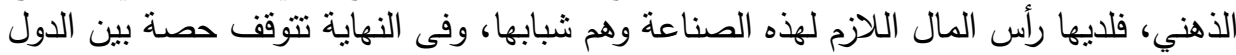
الأعضاء فى اتفاقية أغادير على قدرة منتجاتها على منافسة منتجات دول أوربا الثاديا الثرقية الساعية

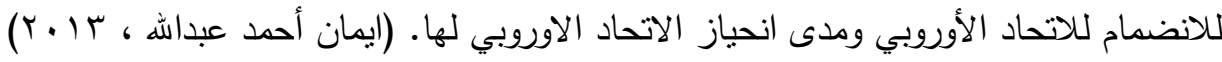

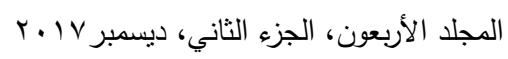




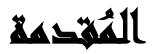

تعد العولمة أبرز ما يشهده العالم من تحولات سريعة، فهى ألة القرن الحادى والعشرين بما

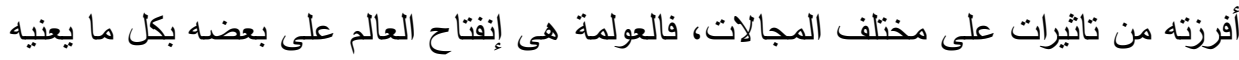
ذلك من سياسات ومفاهيم، حيث ينبغى على الدول النامية التفاعل مع مقتضيات النظام العالمى الجديد ومسايرة نسقه إستجابة لمتطلبات النمو والتتمية ولمسايرة هذه التغييرات والمستجدات،

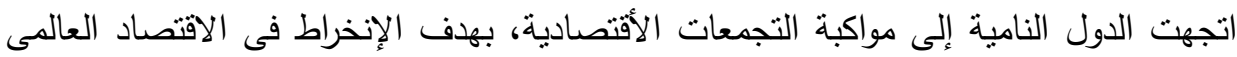
لمواكبة التحولات الناتجة عن ظاهرة العولمة وما يترتب عنها من إتفاقيات دولية، ولا سيما تلك الك

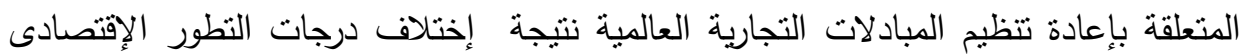

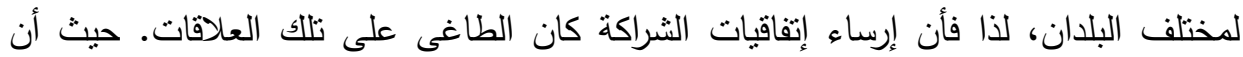
مرحلة العولمة تتطلب نتكيل تكتلات تستعين بها الدول لحماية لنفسها، وتحقيقاً لعناصر القوة

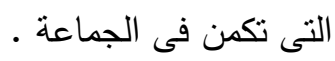

علاقة إتفاقية أغادير بالإتفاقيات الأخرى: تأتي إتفاقية أغادير كخطوة هامة نحو تحقيق أهداف

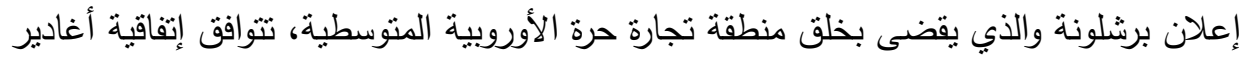

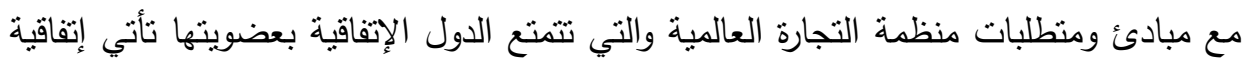
أغادير إتساقاً مع ميثاق جامعة الدول العربية والذي يدعو إلى تعزيز ودعم التعاون العربي

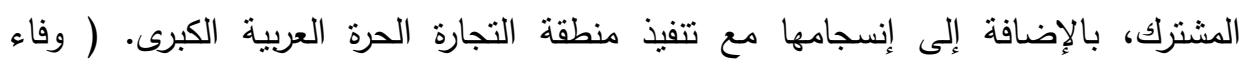

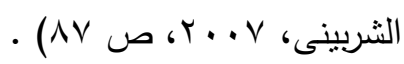

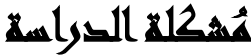

لقد قامت الدول الأعضاء فى اتفاقية أغادير بإنباع بعض السياسات تهدف إلى تتمية الصادرات والواردات بين دول الاتفاقية، ومن بينها فتح أسواق جديدة من خلال عقد اتفاقيات

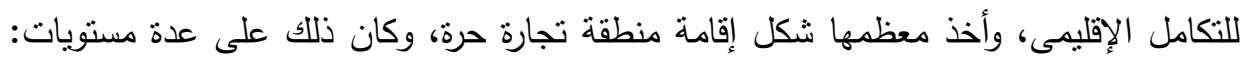

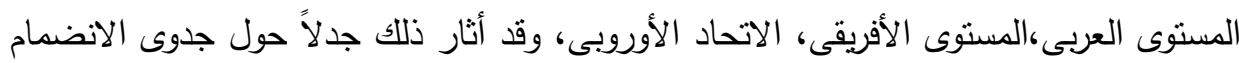

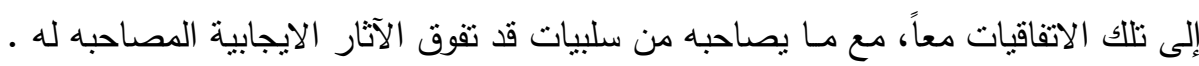
370

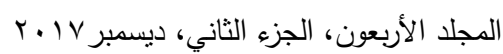


يعانى الاقتصاد داخل دول الإتفاقية من من اختلال هيكلى داخلى واختلال هيكلى خارجى

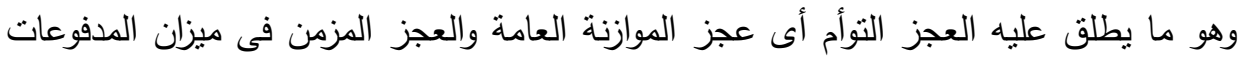

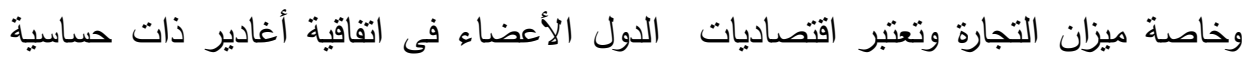
للواردات بمعنى أن معدل نمو الدخل القومى يتأثر بصورة كبيرة بطاقة الاستيراد وتدهور معدلات

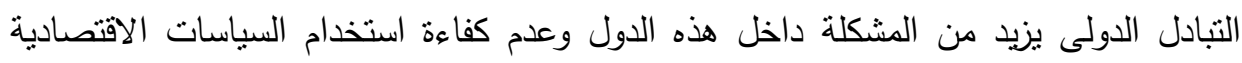
داخل الإثاقية. (أحمد المحجوب: " تحليل وتقييم لور الصادرات فى التتمية الاقتصادية "r . . ب) حيث على الرغم من دخول إتفاقية أغادير والتى تضم أربعة دول عربية وهى مصر

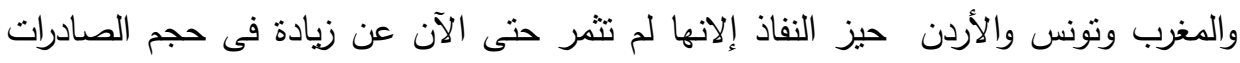

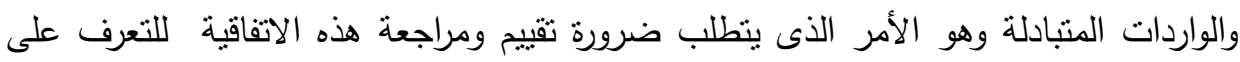

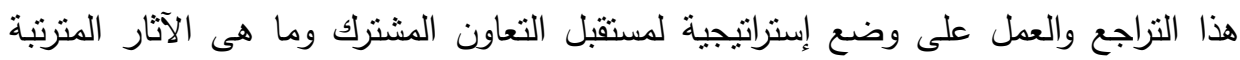

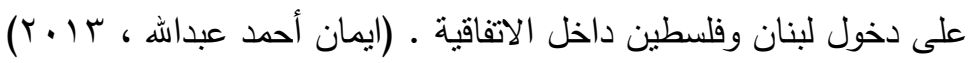

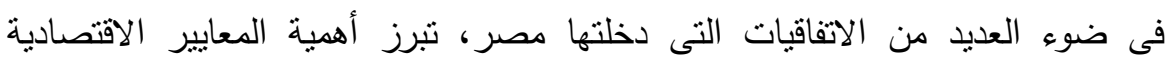

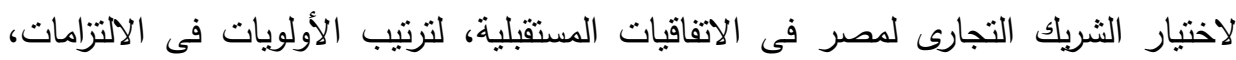

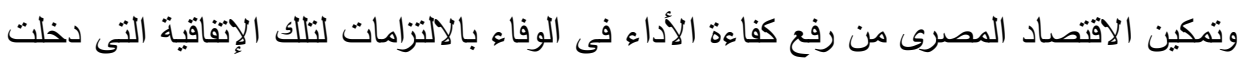

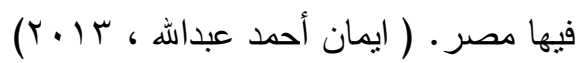

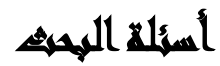

- ما أداء التبادل التجارى فى إطار إتفاقية أغادير العربية ودول الاتحاد الأوروبى؟

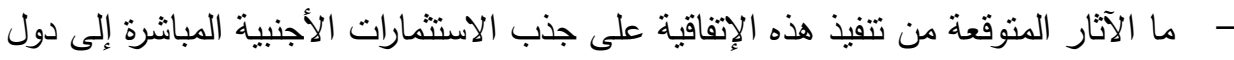
الإتفاقية؟ - ما مقدار الاختلافات بين اقتصاديات كل من مصر ودول الإتفاقية وما هو مستوى قدرتهم التتافسية وتأثير ذلك على التعاون الأقتصادى بينهما؟

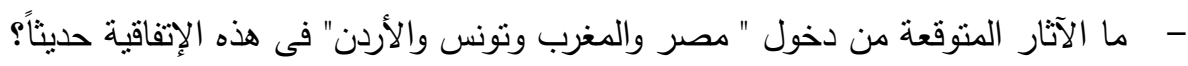


ولذلك أهتمت الدراسة بمشكلة إنخفاض التبادل التجارى بين دول الإتفاقية وهى المشكلة

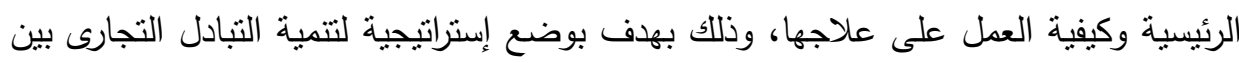
دول الاعضاء إتفاقية أغادير .

\section{اهمهية الصراسلة}

وتأتي أهمية الاراسة الحالية من خلال ما يلي: ( ) الأهمية النظرية: يمثل البحث الحالي إضافة نظرية لمجموع الدراسات التي تطرح الموضوعات الخاصة بوضع استرتيجية زيادة الصادرات فى دول اتفاقية أغادير • r الأهمية التطبيقية: فتتحدد في محاولة التعرف على التعرف على واقع وحجم التبادل التجارى بين الدول الأعضاء فى اتفاقية أغادير وبين الإتحاد الأوربى الهي

\section{أهماهت القراسمة}

تسعى هذه الدارسة إلي تحقيق مجموعة من الأهداف يمكن بلورتها في الآتي:

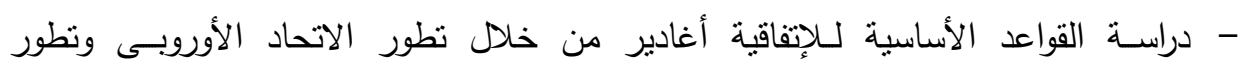
علاقانه بالمنطقة المتوسطية. - التعرف على واقع وحجم التبادل التجارى بين دول إتفاقية أغادير العربية المنوسطة للتبادل الحر وبين الإتحاد الأوربى.

- وضع إستراتجية لزيادة حجم التبادل التجارى مع دول إتفاقية أغادير العربية المتوسطية للتبادل الحر. 


\section{هروض الصواسمة}

اتساقًا مع تساؤلات الدراسة فإن الباحث يعرض عدة فروض يحاول من خلا الإجابة

عليها والإجابة على نساؤلاتها، التوصل إلى أهداف الدراسة، وذللك من خلال الفروض الآنس الآتية:

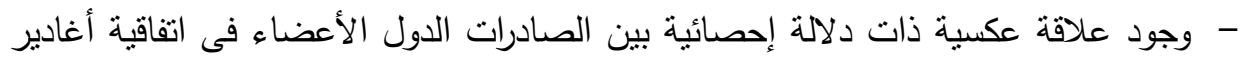

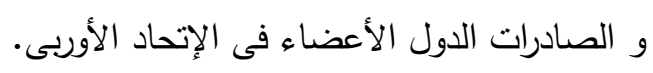

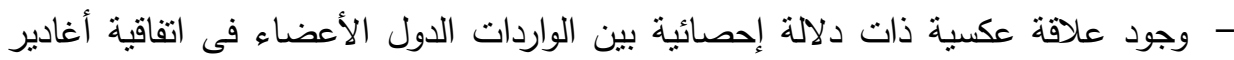

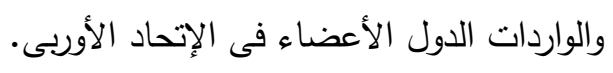

- وجود علاقة عكسية ذات دلالة إحصائية بين التبادل التجارى الدول الأعضاء فى اتفاقية

$$
\text { أغادير والتبادل التجارى الدول الأعضاء فى الإتحاد الأوربى. }
$$

\section{التراسايت الساريها}

زمن سيف سيف الاين عبد الحميد(0 10 ب بعنوان: "دراسة تحليلية للتجارة الخارجية

الزراعية المصرية فى ضوء المتغيرات المعاصرة "

تتاولت هذه الدارسة المتغيرات المحلية والعالمية ذات العلاقة بالتجارة الخارجية الزراعية، لمتغيرات المحلية والعالمية ذات العلاقة بالتجارة الخارجية الزراعية، القاء الضوء على أهم

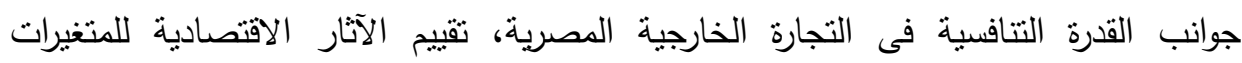
المعاصرة ومحددات التجارة الخارجية الزراعية المصرية وحصر أهم العوامل المؤثرة عليها،

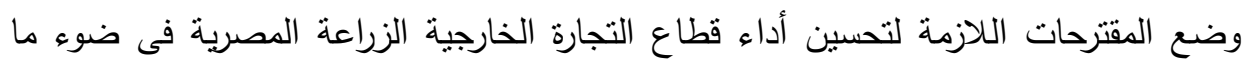
توصلت إليه الدراسة.

توصلت الدراسة إلى بعض النتائج: يوجد معوقات نواجه الصادرات المصرية بوجود تعريفة

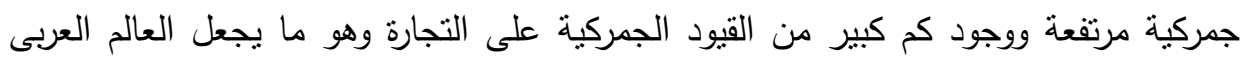

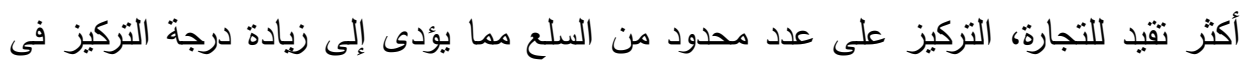

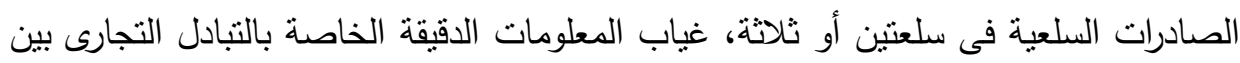
الدول العربية وسائل الدفع بين الدول العربية إذ تتسم المدفوعات بين الدول العربية بلدية بالعلملة 
الأجنبية بالرغم من حاجة الدول العربية إلى تلك العملة مما يجعلها تتجه بصادراتها إلى الدول المتقدمة لتوفير تلك العملة، عدم وجود مواصلات بين الدول العربية مما يؤدى إلى ارتفاع تكاليف النقل، تفاوت الدول العربية من حيث درجات النمو الأقتصادى ومن حيث توزيع عناصر

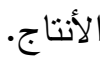

وانتهت الاراسة إلى توصيات أهمها : ضرورة العمل على تحسين الصادرات وخصوصاً فى

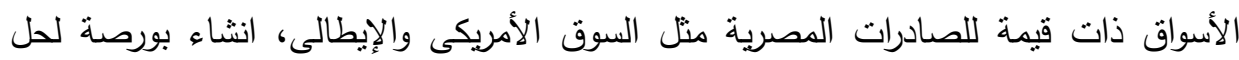

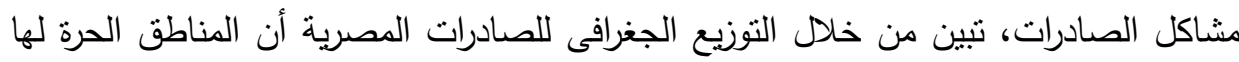

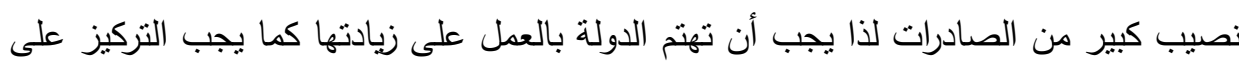

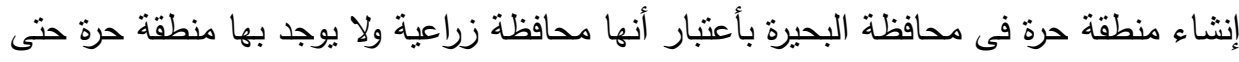

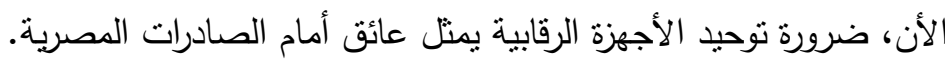

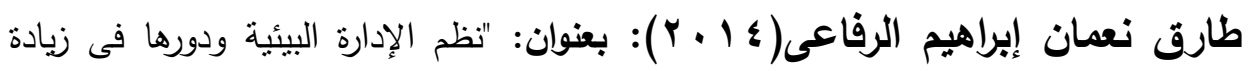
القدرة التتافسية لصادرات الصناعات الغذائية المصرية" رسالة دكتوراه، قسم العلوم الإقتصادية والقانونية والإدارية البيئية، معهد الدراسات والبحوث البيئية، جامعة عين شمس ع ـ ـ ب. تهاف الاراسة إلى التعرف على أثر المحددات البيئية على تطوير وزيادة الصادرات المصرية من السلع الغذائية وإمكانية التوافق مع منطلبات المعايير البيئية للأسواق الخارجية من خلال: دراسة ما هى نظم الإدارة البيئية، دراسة المعايير والاثتراطات البيئية وتأثيرها على زيادة الصادرات المصرية، المعاونة فى حماية البيئة من الاخطار من خلال نظم الإدارة البيئية،

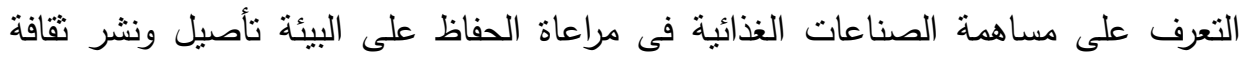
وجودة ونظم الإدارة البيئية دراسة أساليب نطوير القدرة التتافسية للصادرات والمنتجات المصرية عامة والصناعات الغذائية بصفة خاصة. 


\section{توصلت الاراسة إلى بعض النتائج :}

• الأهية البالغة لتحديث الصناعات المصرية لتتلاءم مع الاتجاهات العالمية فى الصناعة

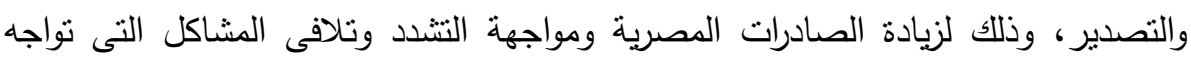

المصدرين المصريين إلى الدول التى تطبق معايير الجودة البيئية.

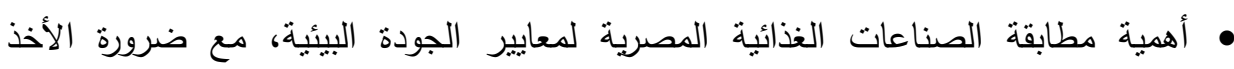
بعمليات التحسين المستمر للقدرات الفنية للمنتجين، والمصدرين الممارسين لإنتاج وتصدير السلع الغذائية. وتزويد الأعضاء بالمواصفات القياسية والثروط الصحية التى تضعها الدول المستوردة عند استيراد السلع والمنتجات الغذائية. • أهمية الاهتمام بالمعايير والاشتراطات البيئية لزيادة الصادرات من الصناعات الغذائية المصرية، وإجراء الدراسات والبحوث النطبيقية النى تخدم تطور الصناعات الغذائية،حيث يلعب البحث دوراً هاماً فى زيادة القدرة التتافسية للصادرات من الصناعات الغذات الغذائية.

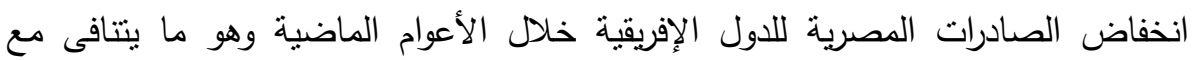
التوجه المصرى القوى حالياً نحو نوطيد العلاقات مع هذه الدول وخاصة فى مجالات تتشيط

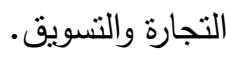
ه رفض الدول المستوردة لبعض الثحنات المصرية فى القطاع الغذائى بسبب عدم مطابقة جودة المنتج للموصفات الخاصة بهذه الدول وتحليل المنتج وعدم مطابقة المواصفات بالإضافة إلى لحدوث تلف بالعبوات نتيجة سوء الأحوال الجوية.

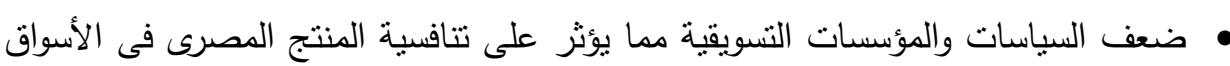
العالمية. • نقص الوعى التصديرى، وعدم توافر مستلزمات الإنتاج مما يزيد من تكلفة زراعة وتصنيع وتصدير المواد الغذائية. نقص البنية الأساسية الخاصة بالتعبئة والثحن ونقص معامل التحاليل وعدم وجود كيانات كبيرة تتعامل مع الأسواق الدولية. 


\section{وانتهت الاراسة إلى توصيات أهمها:}

• التحول إلى الإنتاج النظيف بالانتقاء الجيد لمدخلات الإنتاج والإلتزام بأساليب الإنتاج الزراعى الأكثر كفاءة واستدامة فيما يتعلق باستعمال المبيدات وخفض الأضرار البيئية

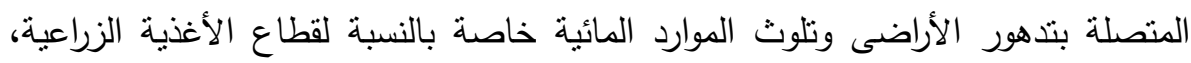
والتأكيد المستمر على جودة الخامات والمكونات. • توفير بيئة ملائمة لدعم تطبيق المعايير والاثتراطات ونظم الإدارة البيئية فى فى مجال

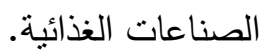
• ضرورة تشجيع الدولة للشركات على الاستثمار فى التكنولوجيا النظيفة وعمليات الإنتاج غير

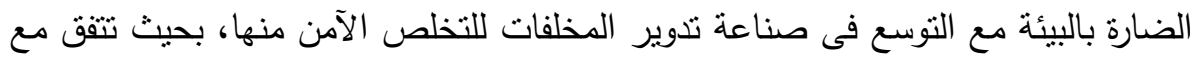

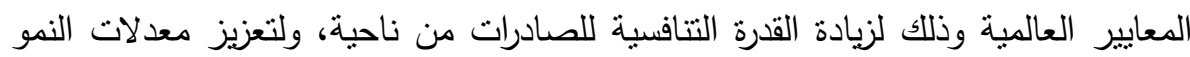
الاقتصادى من ناحية أخرى> تطوير أساليب التعبئة والتغليف مع مراعاة المواصفات العالمية فى هذا المجال، سواء فى الهى مجال التصنيع أو مجال التداول. ه العمل على حل كافة المشكلات التى تواجه المنتجين وخاصة فى الضرائب وضريبة المبيعات والجمارك مع زيادة الإعفاءات الممنوحة لهم.

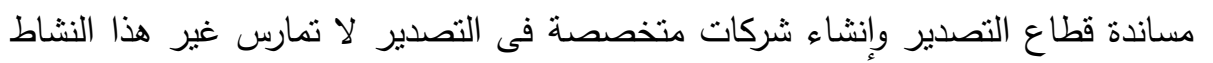
بدعم قوى من الدولة وهو ما فعلته الكثير من الدول منها نونس لخلق كيانات قوية فى في هلئ الأسواق الخارجية. • وضع نظام التصدير والاستيراد يمثل نوعاً من الصفقات المتكافئة.

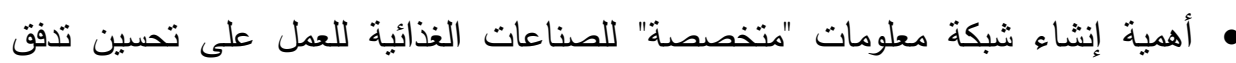
المعرفة والمعلومات والتكنولوجيا بين القطاعات المختلفة حيث يعتمد تعزيز القدرة التتافسية 


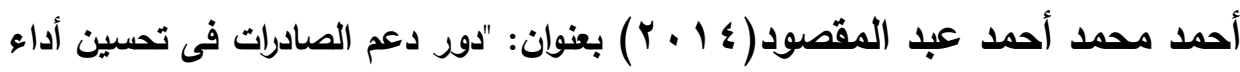
الميزان التجارى المصرى دراسة مقارنة:- مصر - الصين - تونس ". يمكن إبراز أهم أهداف الدراسة في الأتى:

• تقييم دور صندوق تنمية الصادرات فى زيادو حجم الصادرات المصرية ورفع قدرتها التنافسية

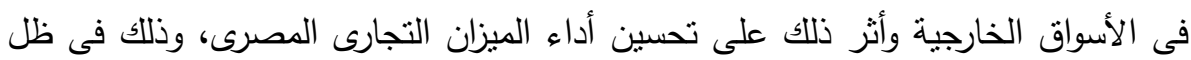
قواعد منظمة التجارة العالمية • التعرف على أثز تخصيص الدعم والمساندة التصديرية، التى يقدمه صندوق تتمية الصادرات إلى المنتجين والمصدرين المصرين، على معدل نمو الصادرات المصرية وخاصة السلعية غير البترولية . (البين إيجاد آلية فعالة لتقديم هذا الدعم وهذه المساندة للصادرات بإعتبارها وسيلة أساسية لدعم

تتافسية المنتج المصرى الذى يواجه منافسه شرسة سواء فى السوق المحلية أو العمالية . توصلت الدراسة إلى بعض النتائج:

• تواضع أداء صندوق تتمية الصادرات المصرية،على الرغم من دوره الملموسفى تحقيق بوفن

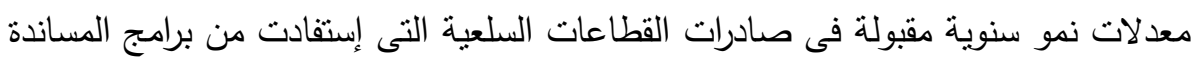
المالية التى يقدمها. • الإعتماد الكامل لأغلب المنتجين والمصدرين الذين إستفادوا من هذه المساندة على هذا الدعم، فعلى على الرغم من دور المساندة الملموس فى تخفيف الأعباء عن كاهل المنتجين

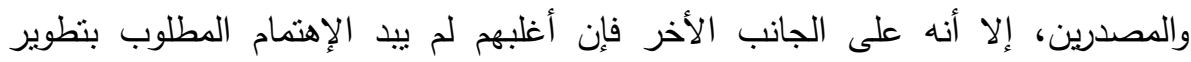
منتجاتهم وجعلها أكثر تنافسية فى الأسواق الدولية.

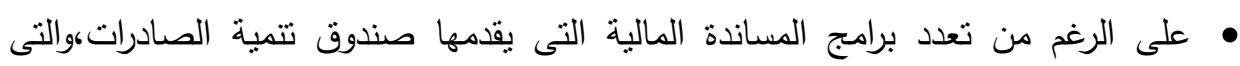
تساهم فى تخفيف الأعباء عن المنتجين والمصدرين، علاوة على الجهود الأخرى المبذولة

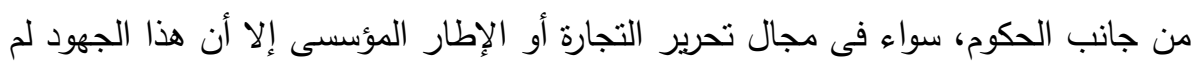

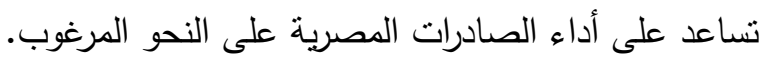


• أوضحت المؤشرات والإحصاءات أن هناك تأثثر ملموس ومنواضع للمساندة التصديرية على التى

تحسن أداء الميزان التجارى المصرى، وذلك من خلا معدلات منات النمو السنوية فى صادرات

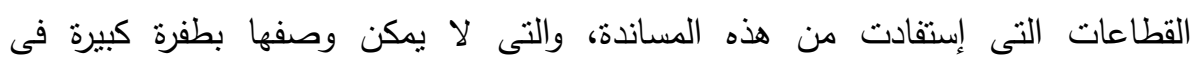

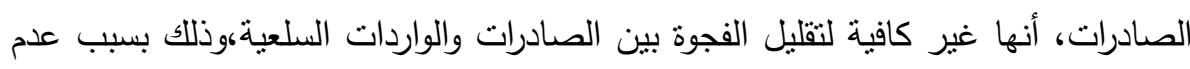

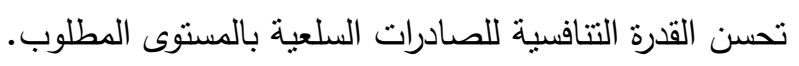

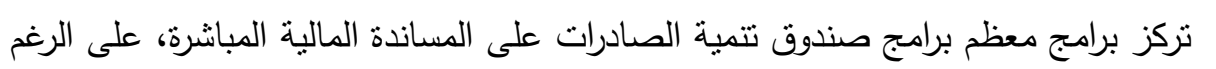

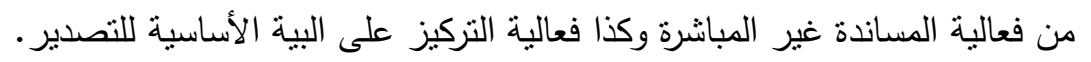

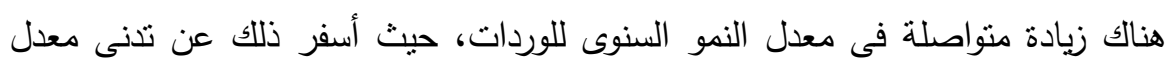

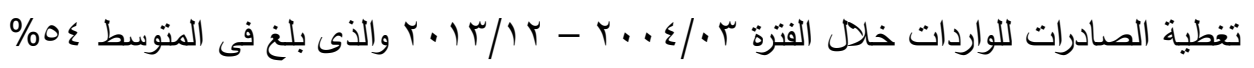
تقريباً. تعد تجربة الصين فى الإصلاح الاقتصادى والإنفتاح على العالم من التجارب الفريدة من

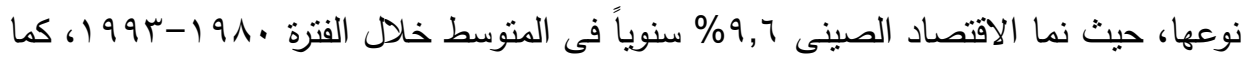

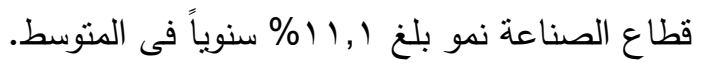
وانتهت الدراسة إلى توصيات أهمها: • تكثيف الإهتمام بالثركات الإنتاجية والتصديرية الصغيرة والمتوسطة القادرة على الإنتاج من

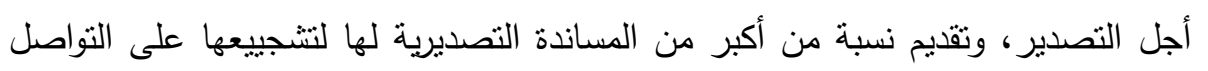

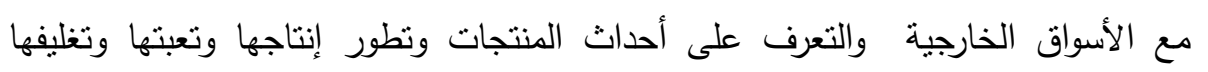
والمعايير المطلوبة دولياً. تخفيض نسبة الدعم المالى المقدم للإشتراك فى المعارض الخارجية للشركات الكبيرة التى

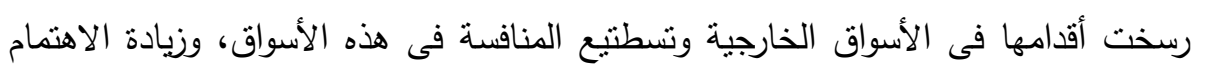

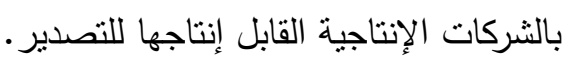


تفعيل دور مركز تحديث الصناعة وتوجيه نسبة كبيرة من المساندة التصديرية التى يقدمها

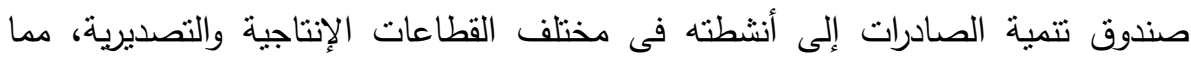

يساهم فى زيادة القدرة التتافسية للصادرات المصرية الصناعية وتتميتها. • تحويل أغلب المساندة المالية التصديرية المباثرة إلى دعم غير مباشرة، كما هو الحال فى بعض الدول منل الصين وتونس وبعض دول الإتحاد الأوربى.

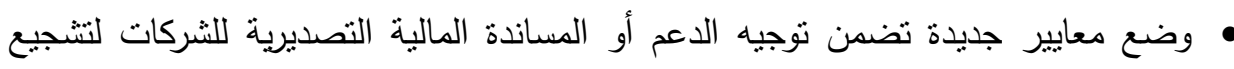

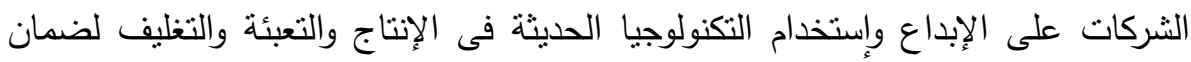
ميزة وطنية تتافسية فى الصناعات الرائدة.

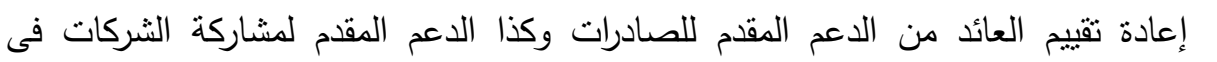
المعارض الخارجية من خلال قيمة صادرتها المحققة خلال سنة على الأكثر، ومدى نطور منتجاتها وإستخدامها لتكنولوجيا إنتاجية جديدة، ومدى إلتزامها بمعايير الجودة الدولية، ومقارنة ذلك مع المساندة المالية التصديرية المقدمة لهذه الشركات. زيادة الإهنمانت بالبنية الأساسية للتصدير التى من شأنها تطوير المنتج المصرى وجعله أكثر

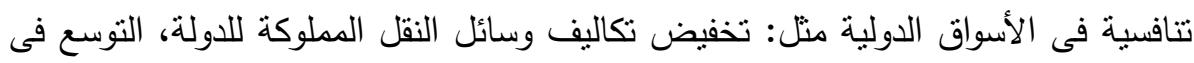

$$
\text { الدعم المالى المخصص للساحة. }
$$

ما يضيفه موضوع الدراسة إلى الدراسات السابقة:

ازدياد الاهتمام المتعلقة بالتبادل التجارى كونها عامل مهم فى الاقتصاديات هولاء الدول. • • اقتراح إستراتيجية مقترحة لتتمية التبادل التجارى بين دول إتفاقية أغادير •

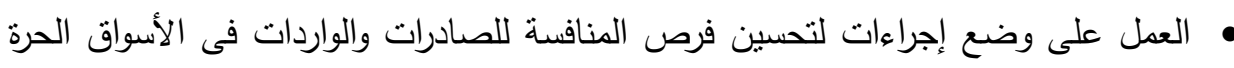
فى اتفاقية العربية المتوسطية للتبادل الحر . • العمل على إيجاد حلول للمعوقات الاقتصادية والتنشريعية والامنية للاستفادة بالوجه الأمتل بإتفاقية العربية المتوسطية للتبادل الحر. •الاستفادة من التجارب الدول المتقدمة فى التبادل التجارى الخاصة فى هذه الاتفاقيات وزيادة القدرة التتافية بهذه الدول المتقدمة. 


\section{الإسلار اللنظليه}

\section{xalyall xh}

حيث يتتاول الباحثين في دراستهم لأدوات التحليل الإحصائى المستخدمة فى مجال التجارة

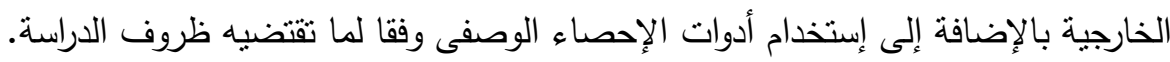
وذلك من خلال دراسة النقاط التالية: تأصيل لمفهوم اتفاقية أغادير ويتم تناول:

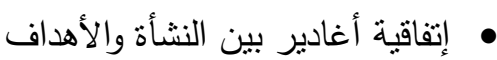

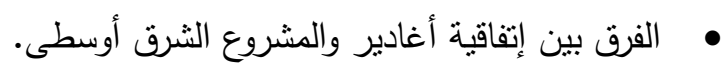$$
\text { • • • • آليات السياسه المتوسطية الثاملة حيث يتم تتاول: }
$$$$
\text { م الحوار العربى الأوبى }
$$

o

$$
\text { O ت توسيع الإتحاد الأوربى شرقا (سياسة الجوار) }
$$

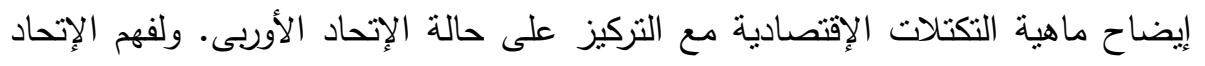

الأوربى بشكل أكبر يتم افراد مبحث مستقل عن المعلومات السياسية الأساسية. تحليل أهم محتويات الإتفاقيات للدول محل الدراسة (مصر - تونس - المغرب - الأردن)

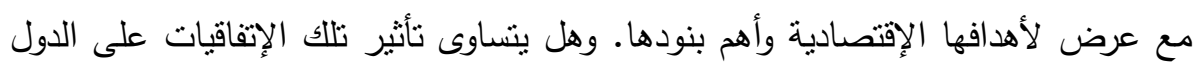
المختلفة.

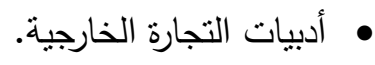

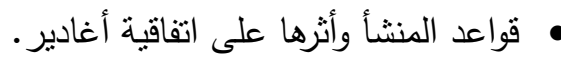

• • تحليل إحصائى عن صادرات وواردات كل دولة من الدول محل الدراسة.

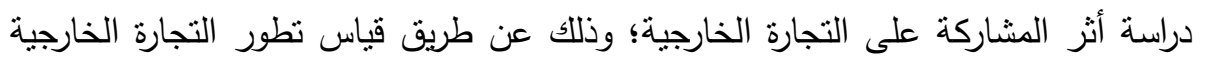

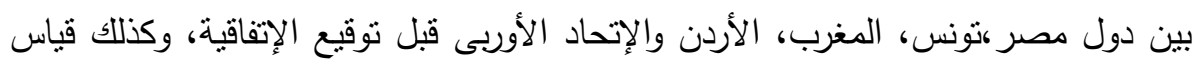

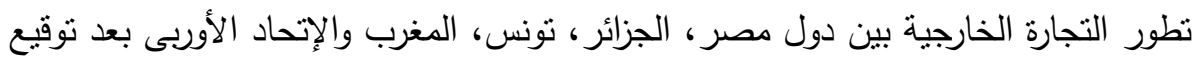
الإتفاقية. أى تقيما للإتفاقيات بالاعتماد على تطور التجاره بين الطرفين. 


\section{لجزاءاهي التراسلة}

حدود الدراسة:

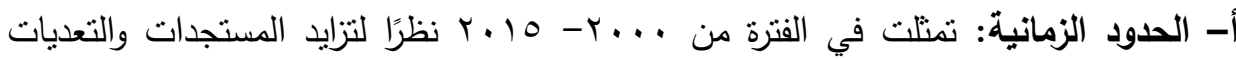
على البيانات الفترة موضوع الدراسة. ب- الحدود المكانية: يتمنل النطاق المكاني للاراسة مصر ودول الاتفاقية وهى (تونس،

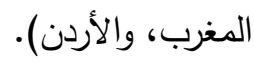

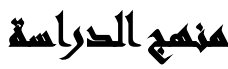

المنهج الوصفى: بدراسة أهم المؤشرات الاقتصادية للتبادل التجارى مع دول إتفاقية أغادير العربية المتوسطية للتبادل الحر وكيفية تتمية التبادل التجارى لزيادة الاستثمارات الأجنبية والإستفادة بإجبيات هذه الإتفاقية.

المنهج التحليلى: بدراسة الاسباب التى تؤدى إلى زيادة حصيلة التبادل التجارى لدول إتفاقية أغادير العربية المتوسطية للتبادل الحر. المنهج الكمى: بدراسة حصيلة التبادل التجارى فى الاعوام السابقة مع دول إتفاقية العربية المتوسطية للتبادل الحر قبل وبعد الإتفاقية. 


\section{نمتأيج الصراسلا}

نقييم لاثار إنفاقية أغادير فى كل من مصر ، تونس الاردن، الدغرب
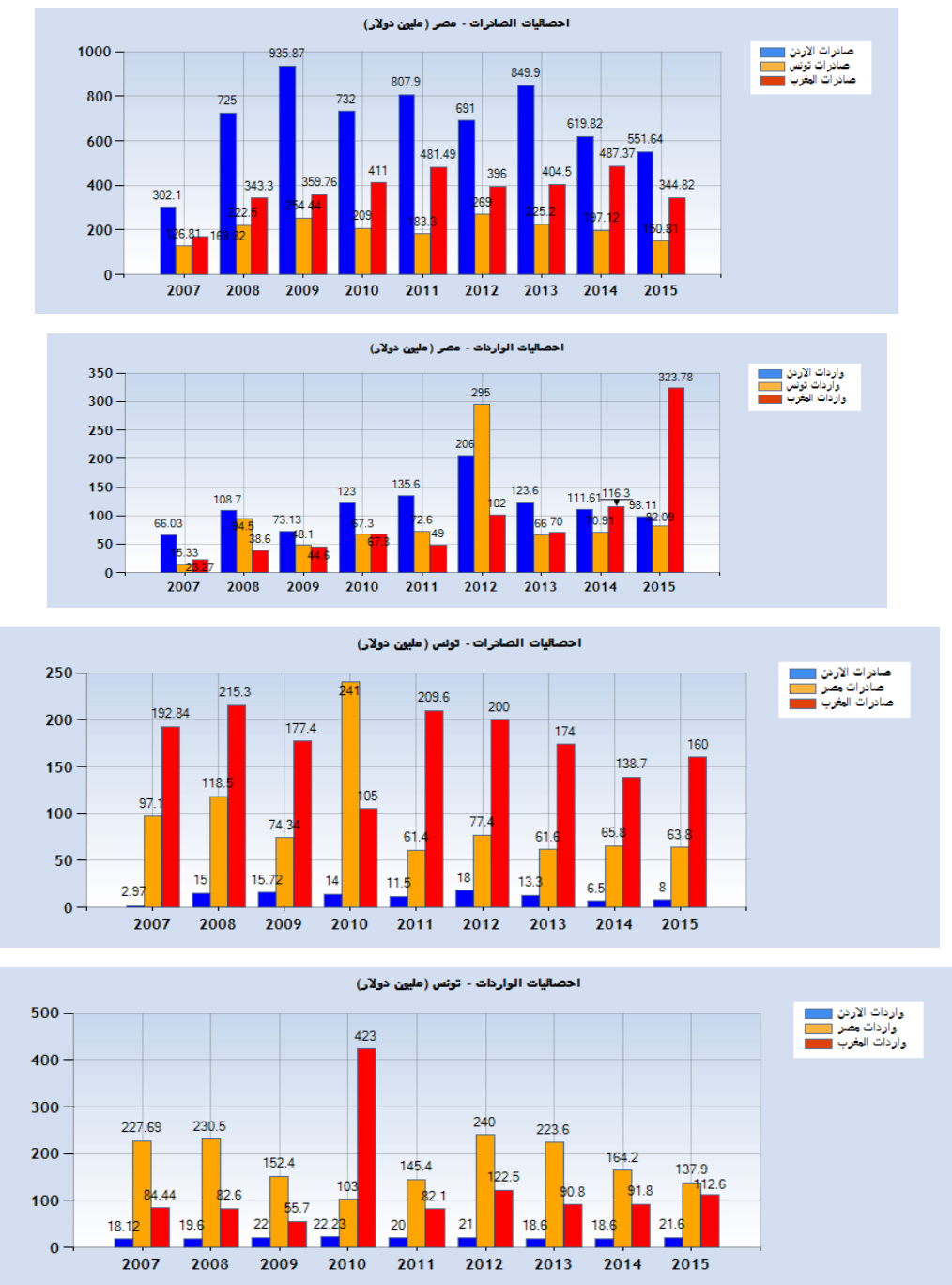


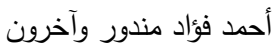
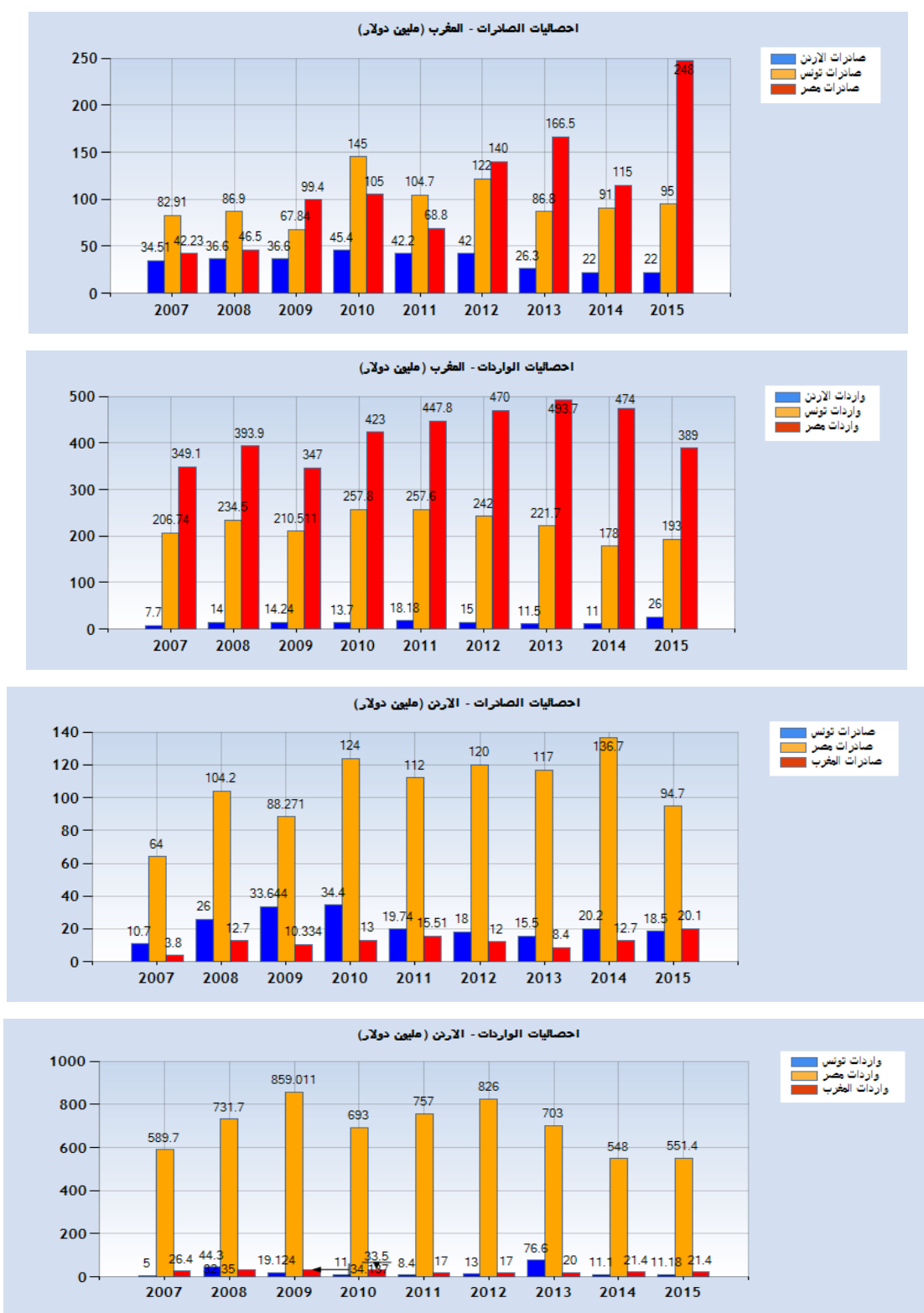

http://www.agadiragreement.org/Pages/viewpage.aspx?pageID= المصدر

$$
\text { المجلد الأربعون، الجزء الثاني، ديسمبر V Y r T }
$$


عند عقد مقارنة بين مكاسب المشاركة المصرية الأوروبية ونظيراتها التى حصلت عليها تونس والمغرب والاردن وهى دول لا تملك سوقاً بحجم السوق المصدرة - نجد أن تونس دخلت

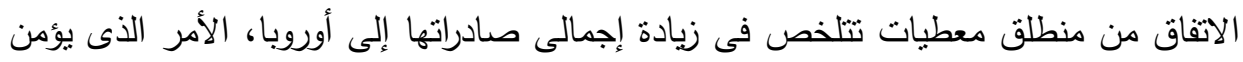

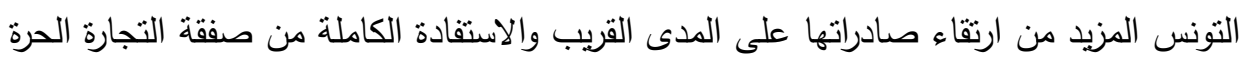
مع الاتحاد الأوروبى، خاصة وأن العجز فى الميزان التجارى مع أوروبا يتم تغطيته من خلاءل الته

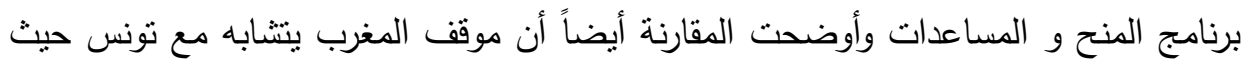

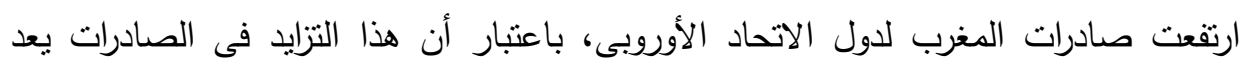

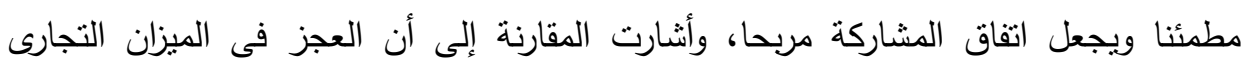

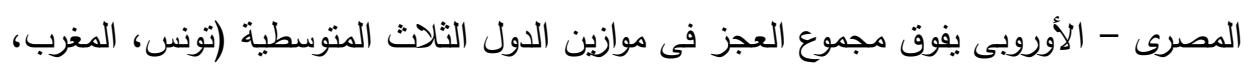

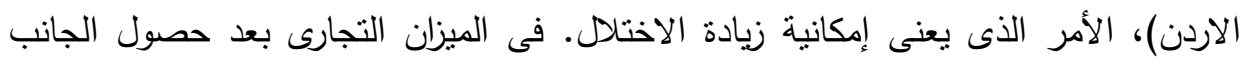

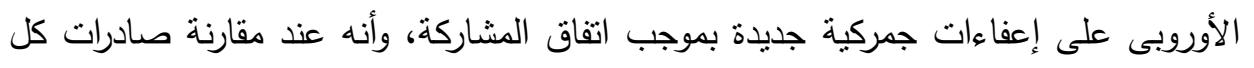

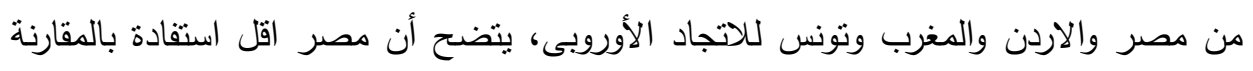

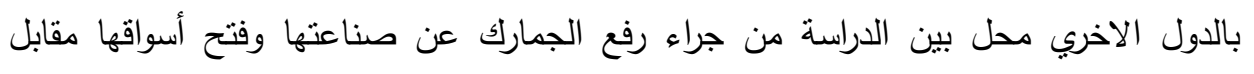
تتنازل الاتحاد الأوروبى قيمة الجمارك على صادرات مصر بالكامل لدول الاتحاد الأوروبي.

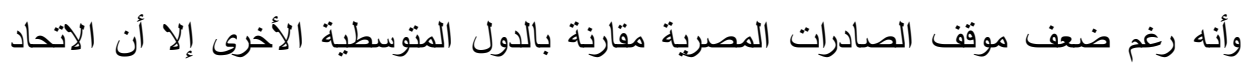

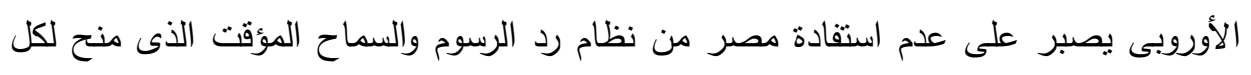
من تونس والمغرب، الأمر الذى سوف يزيد من تكاليف المنتجات المصدرة، ويزيد بالمنافسة

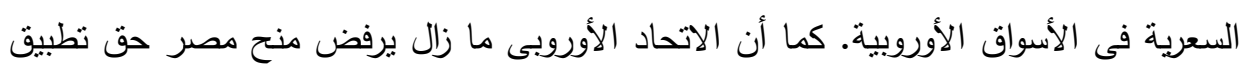

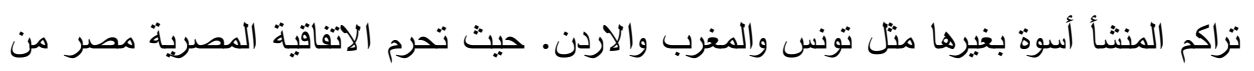

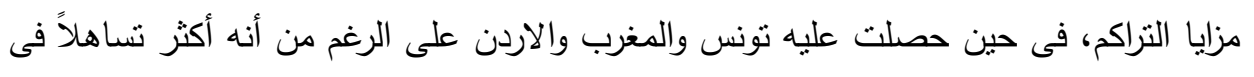
إضفاء صفة المنشأ على المنتج المصري، كما ترصد التقارير الرسمية أيضا مشكلات كبيرة

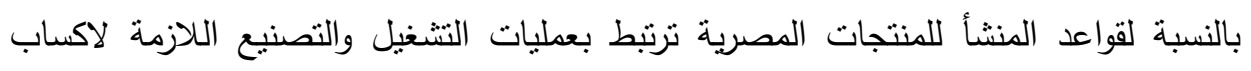

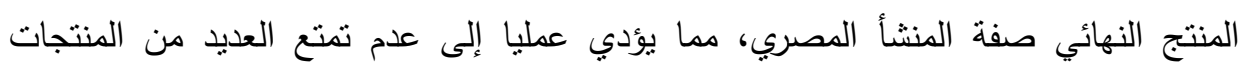


والصناعات المصرية وبالتالي السلع المصدرة للاتحاد الأوروبي بالإعفاء الجمركي المقرر ويحرم

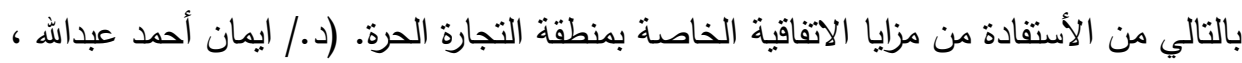

وأنه عند مقارنة المكاسب التى حصل عليها المفاوض المصرى بالمكاسب التى حصلت

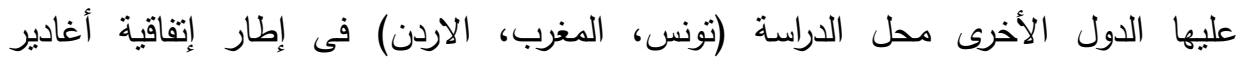

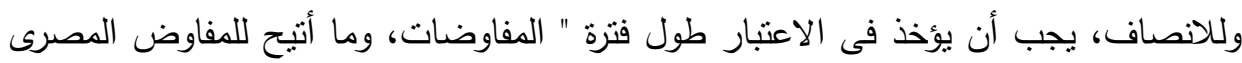

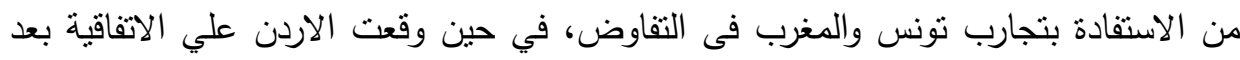

- إن اتفاقيات المشاركة تتيح للدول المتوسطية فرصة الحصول على المنح والمعونات مصر

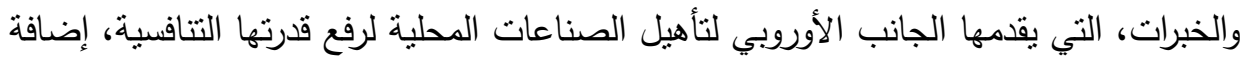
إلى أن: الاتفاقيات تفتح أمام الدول المتوسطية سوقاً واسعة من مواطني أوروبا ـ الاتحاد الأوروبي

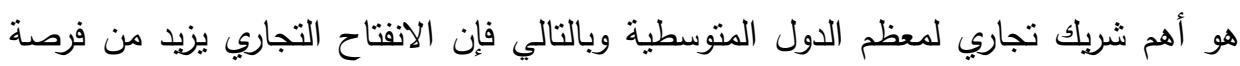
خلق التجارة، بينما ينخفض تأثير تحويل التجارة، وهذا لأن التجارة تتم أساساً مع الثريك لأنيك

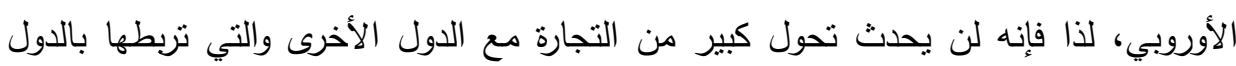

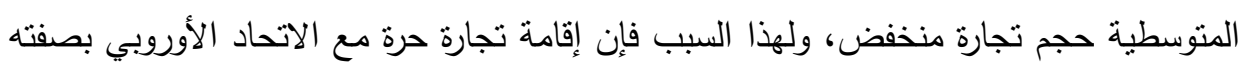

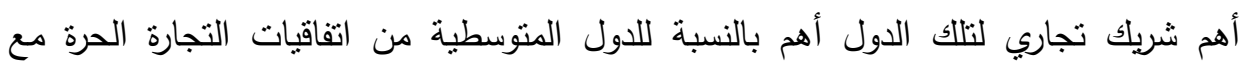
المناطق الأخرى ولتكن الولايات المتحدة الأمريكية مثنا.

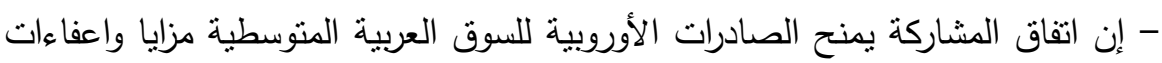

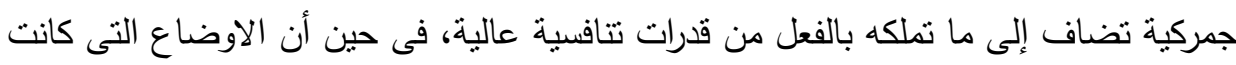

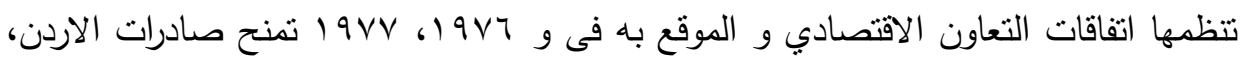
تونس، المغرب، مصر مزايا تصل الى حد الاعفاء الكامل من الجمارك دون أن ثقدم تلك الدول

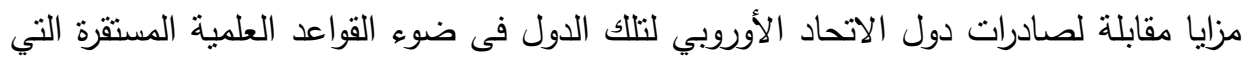


لا تسمح للأكثر تقدما والأعلى تتافسية الحصول على نفس المزايا التي يحصل عليها الأقل تقدماً والأقل تتافسية. - رغم الميزة النسبية التي تتمتع بها مصر فيما يتعلق بعنصر العمالة إلا أن هذا العنصر

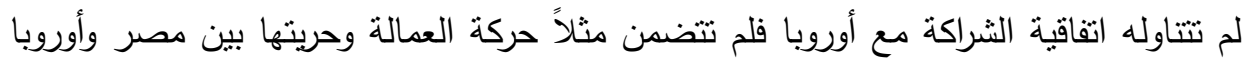

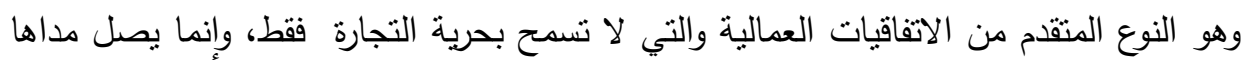
إلى حرية حركة العمالة ونوحيد العملة، وهذا عكس اتفاقية نونس حيث أنها افردت لذلك بندان التها

$$
\text { خاصا وهذا لم يحدث في الاتفاقية المصرية. }
$$

- إن المنافسة فى إطار المشاركة ستكون بين الدول المتوسطية بعضها البعض وليس بين

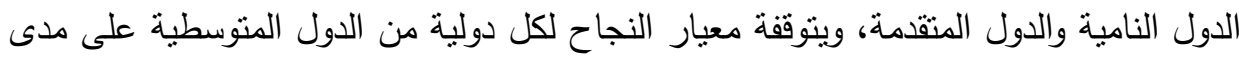
قدرتها على جذب المزيد من الاستثمارات الأجنبية المباشرة من خلال الثركات المتعددة الجنسيات والتي تمتلك الدول الأوروبية جزء كبير منها.

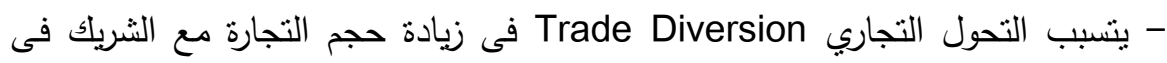
أنفاقية التجارة الحرة على حساب شركاء التجارة الأخرين، مما يسمح بامكانية تشوه الأسعار Price Distortion للسلع الأوروبية من جانب المنتجين والمستوردين وبالطبع من المستهلكين.

\section{الآثار المتوقعة على ملف الصناعة:}

- انفتاح السوق العربي المتوسطي على الصناعة الأوروبية فيما عدا الصناعات الغذائية رغم عدم التكافؤ بين الصناعة العربية المنوسطية والصناعة الأوروبية نظراً للكفاءة الإنتاجية

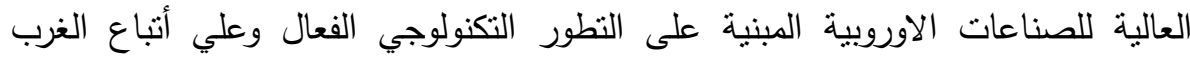
لسياسات صناعية منطورة، من شأنه أن يعمل علي منافسة المنتجات المحلية، ومن ثم

$$
\text { فهناك ضرورة لترافق التحديث مع التحرير . }
$$

- حرمان الخزانة العامة من بعض الموارد نظراً لتخفيض في الرسوم الجمركية. - ارتفاع تكلفة أنتاج السلع الصناعية العربية لتحميل مدخلاتها الكثير من الأعباء. 
- التراكم الخاص بقواعد المنشأ ليس فى صالح الدول العربية المتوسطية وهناك مطالبة بتراكم

$$
\text { كلي مع الدول العربية سواء المشاركة في الاتفاقية أو الغير مشاركة. }
$$

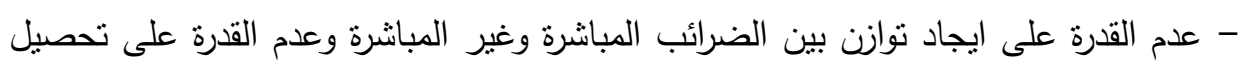
الضرائب الخاصة وتهرب الممولين مما يجبر الحكومة أن تلجأ إلى ضريبة مبيعات.

- لم يعط لقضية التسويق الاهتمام الكافي، فكيف يتم التسويق وكيف يتم الارتباط بمراكز التوزيع

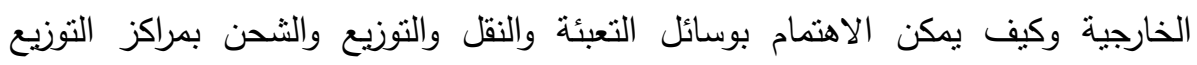

- عدم وجود تتوع كافي للسلع الفتح آفاق التصدير، والذي يعد ضمن المشاكل الحالية فنجاح

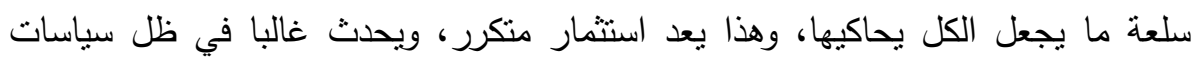

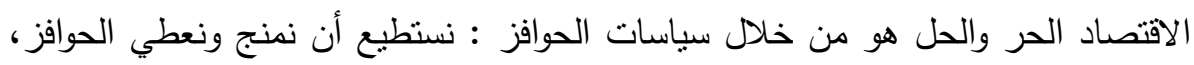

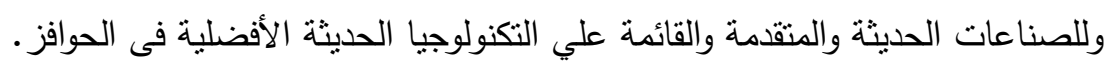

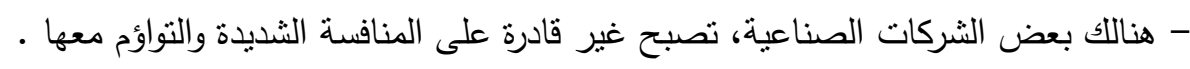
- يظهر الخلل الثديد فى القواعد المنظمة لانثاء منطقة التجارة الحرة من مراجعة قوائم اعفاء

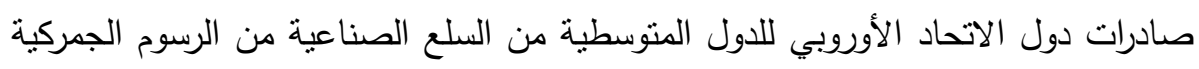

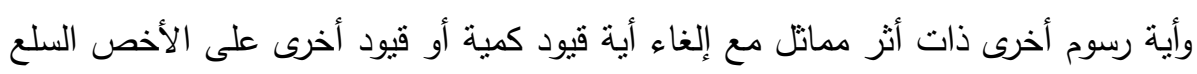

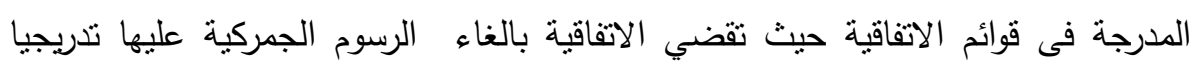

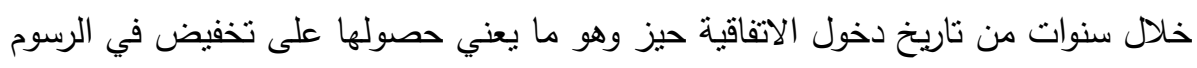
الجمركية عند التوقيع مباشرة لتصل إلى الصفر بعد سنوات وخطورة ما تمثلكه من منافسة

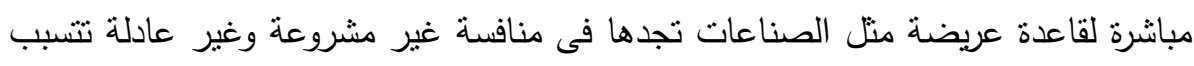
فى إفلاس وتوقف الكثير عن العمل والنشاط

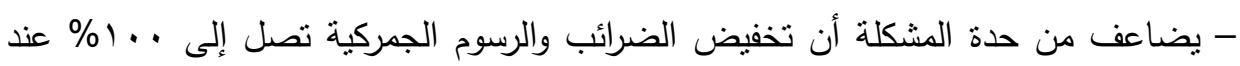

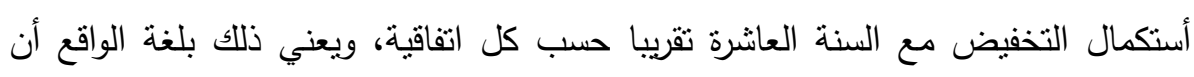
حسابات الجانب الأكبر من الأرباح الدول الاتحاد الأوروبي في حالة الصادرات الصناعية

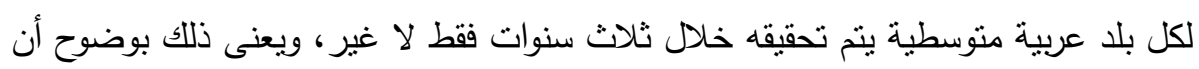

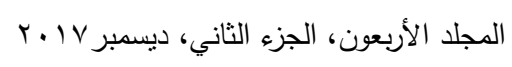


الأرباح والخسائر تخضع لنظرية الهرم المقلوب حيث تفتح أبواب السوق للدول العربية

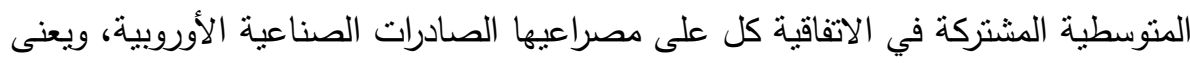
أيضا أن الصناعة المتوسطية لا تعطى الفرصة الملائمة لمواجهة المنافسة القوية من الدول الأوروبية

\section{الآثار المتوقعة على ملف السلع الزراعية:}

- ليس هناك نظام لرد الرسوم المباشرة والغير مباشرة على المدخلات الزراعية في حين أن

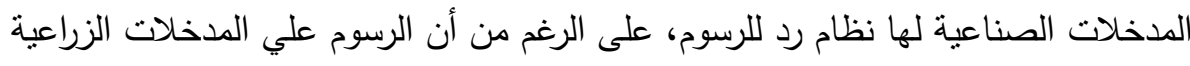

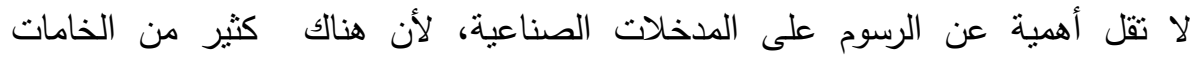
المستوردة المستخدمة فى زراعة الخامات الزراعية ويدفع عنه جمارك وضريبة مبيعات ولا

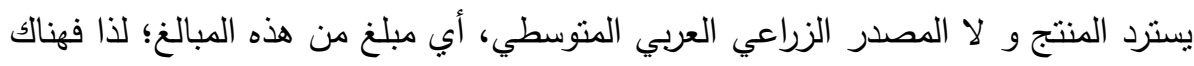
مطالبة بمساواة قطاع الزراعة بقطاع الصناعة.

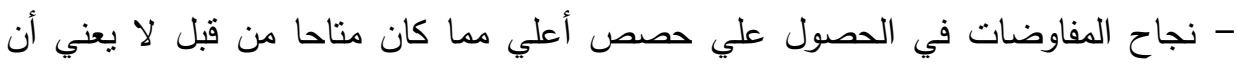
السوق الأوروبية مفتوحة لصادرات المنتجات الزراعية؛ فالسياسة الزراعية الأوروبية حمائية

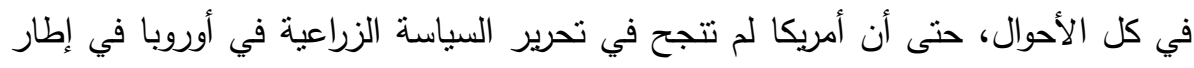
اتفاق الجات. -إن قائمة بالغة النتّد من القيود تقرض علي الصادرات العربية المتوسطية، مما يخل بجميع حسابات المكسب والخسارة ويجعل منها حسبة واحدة فقط تصب في خانة دول الاتحاد الأوروبي وهي قيود لا مثيل لها. -تتجلي وتظهر قيود الاتفاقية في مجال الزراعة بشكل واضح من مقارنة الإمكانات الضخمة

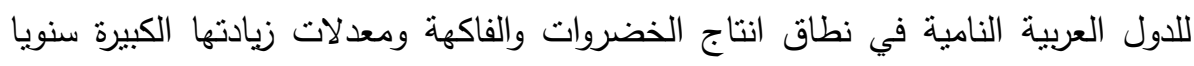
وحاجتها الثنديدة للأسواق الخارجية للتصريف بالحصص المحدودة و المقررة في الاتفاقية 
-الملف الزراعي يجب أن ينظر إليه في ضوء مرونة الإنتاج الزراعي العربي المتوسطي. رغم

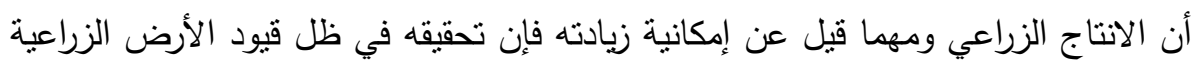
والموارد المائية يظل محدود مقارنة بالنشاط الصناعي.

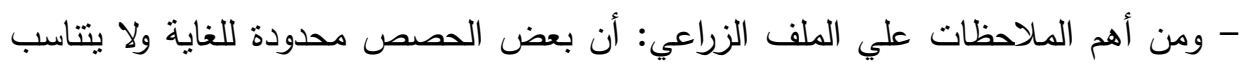
مع امكانيتات التصدير ، كذلك فأن اسعار الدخول المحدودة لبعض السلع مرتفعة، مما يمثل

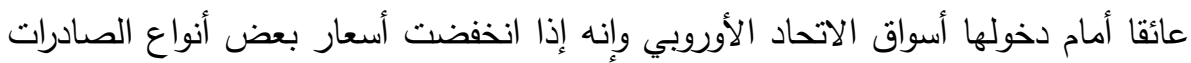

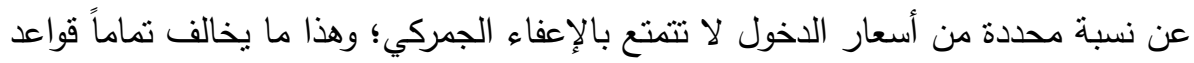
اقتصاديات السوق.

- هناك تتاقضات بالملف الزراعي وبكل جوانبه، وهناك قصور شديد في مواده وبنوده علي

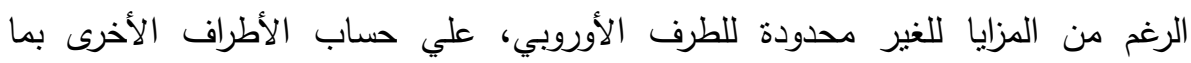
يستوجب إدخال تعديلات جذرية علية في ضوء المطالب المقدمة بالفعل والتي لم تجد سوي المبري التجاهل علي مدي جلسات التفاوض. حيث طالبت مصر بالحصول علي حصص اضله اضفافية تتجاوز التدفقات التقليدية، لكن دولة أوروبية أعربت عن خضيتها من مطالبة الدول الأخرى المشاركة في الاتفاقية بذلك.

\section{الآثار المتوقعة علي ملف الصناعات الغذائية:}

- أن المطالبة بمضاعفة صادرات الدول محل الدراسة خاصة والدول العربية عامة يواجههة عقبة أنه لو انفتح السوق الأوروبي سينفتح أمام الجميع؛ وهذا لا يخدم الموقف الخاص بالدول محل الدراسة خاصة وإنما يخدم مصالح الدول الزراعية الكبرى علي الاطلاق.

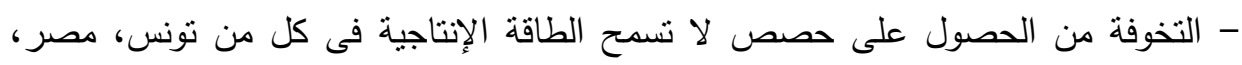
المغرب، الاردن بإنتاجها مما يجعل تحديد تلك الحصص حبراً عسى ورق، وفى هذه الحالة فإن فرض الرسوم التعويضية مقابل ما يقدم من دعم أوروبي للسلعة ما سيكون لا فائدة منه.

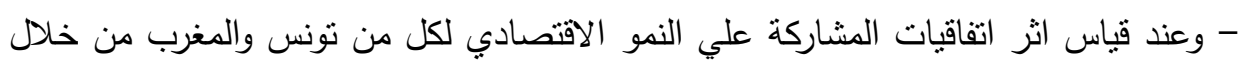
تحرير التجارة وجد أيجابية الاتفاقيات في هذا الخصوص، من خلاد تفسير اتجاهات تأثير التهات التجارة علي الرفاهية الاقتصادية وكذلك فان تأثثر تحرير التجارة في أطار اتفاقيات إتفاقية 
أغادير وخاصة لتونس والمغرب كان ايجابيا علي الاداء الاقتصادي العام. في حين تعد

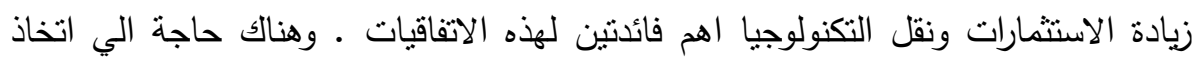
تونس والمغرب بعض الاجراءات المساعدة لاستكمال ما جاء في الاتفاقية وتعظيم الفائدة منها - تتباين النظم الاقتصادية الأوروبية والعربية الامر الذي يجعل وحدة السوق سببا فسي اتساع

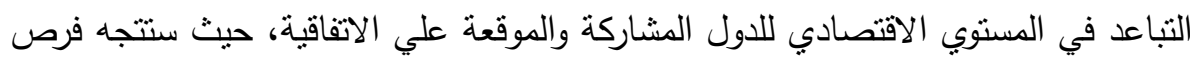

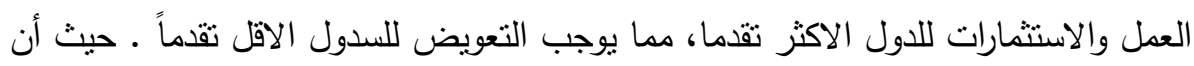
السير بسرعتين مختلفتين أحيانا ما يؤثر سلبا علسي تطور عملية المشاركة الاوروبية كنتيجة للتفاوت بين طرفي الاتفاقية أي الطرف الاوروبي والطرفي العربي المنوسطي. - عدم الاتفاق السياسي بين كل الدول الاعضاء في الاتحاد الاوروبي، أحيانا مما يؤثر بشكل

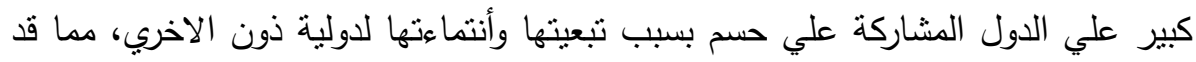

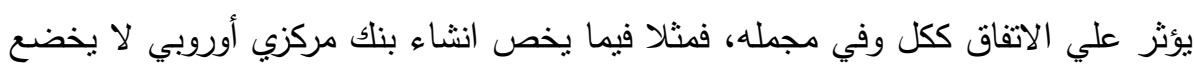
لسيطرة الدول الاعضاء، والذي وافقت عليه المانيا: وفرنسا وايطاليا بينما عارضته بونهاء بريطانيا

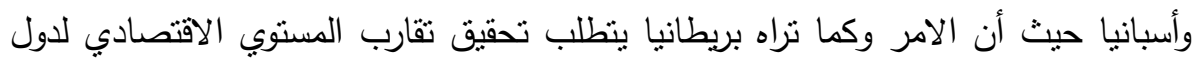
الاتحاد قبل أنشاء البنك المركزي.

ان التعاون الدولي الفعال من أجل التتمية لا يمكن أن ينجح الا اذا اتخذته الدول

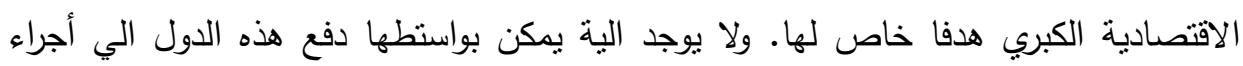

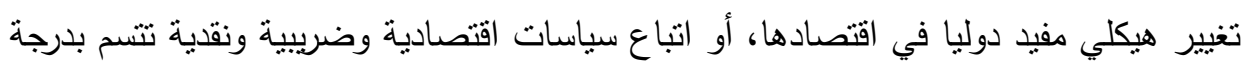
أكبر من المسؤلية علي المستوي الدولي. - فإن المداولات والمناقشات الدولية كثثرا ما تزيد وضوح القضايا المطروحة لدي لرأي

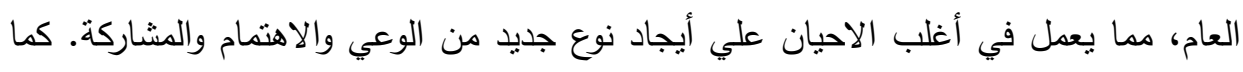
حدث مؤخرا بالنسبة إنفاقية أغادير والجدل القائم حولها. 
- تعتبر اتفاقية الثراكة نطور طبيعي للسياسة الأوروبية الزراعية (GAP)، حيث أن

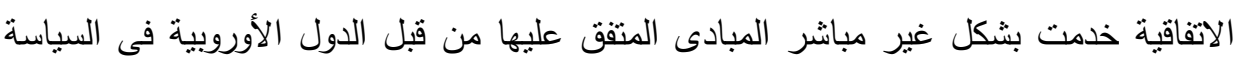

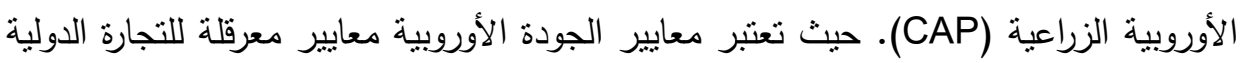
فى السلع الزراعية، وهي بشكل غير مباشر قيود على الصادرات الزراعية من الدول المنوسطية.

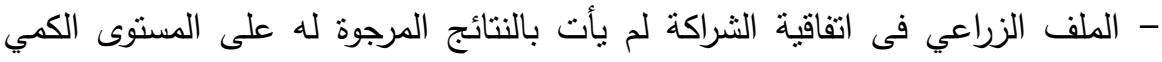

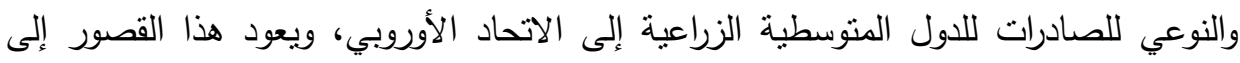

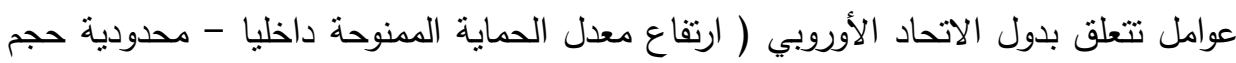
الحصص وفترات السماح- وأرتفاع سعر الدخول).

- بالنسبة لمدى تأثير اتفاقية الثراكة على قدرة التنافسية للمحاصيل الزراعية، فإننا نلاحظ أن اتفاقية الثراكة زادت من القدرة التتافسية لبعض المحاصيل الزراعية لدول المتوسط فى لئل

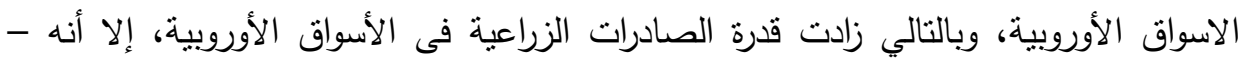

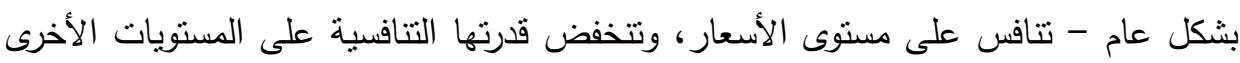

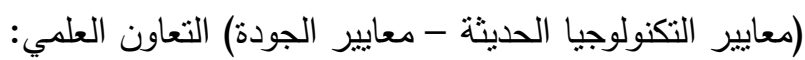
- لمصر الحق وفقا للمادة "ب؟" فى الاشتراك فى مشروعات البحث العلمي الأوروبية وفقاً

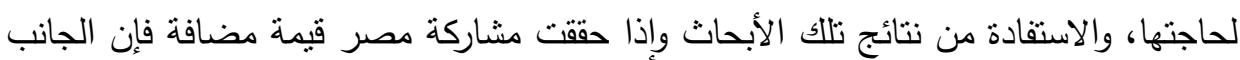
الأوروبي يقوم بتمويل نلك المشاركة كما نسنطيع مصر المشاركة فى برنامج التعاون الدولي

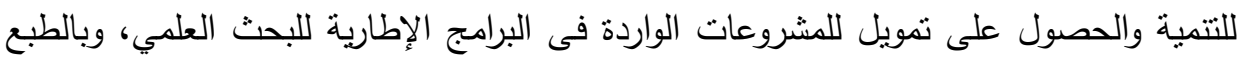

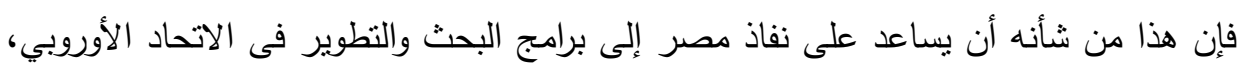

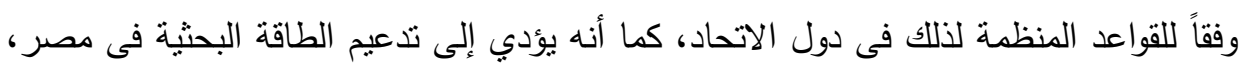
وحث المستحدثات التكنولوجية ونقل التكنولوجيات الجديدة ونشر المعرفة. - يركز التعاون المالي على دعم الإصلاحات التي تستهدف تحديث الاقتصاد وتعزيز القطاع الخاص، وإعادة هيكلة الصناعة، كما انه يدعم تتفيذ السياسات المتعلقة بالقطاع الإعاع

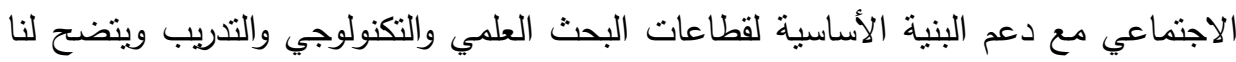
بما ثقدم أنه بالرغم من أن المبادرة الأوروبية نوفر مساعدات ومنح فنبة مصممة لتحسين قدرات 
البحوث المحلية والنطوير وتتثمل برامج للنطوير التكنولوجيا للمؤسسات القائمة إلا أن الثواهد تثنير إلى أن حوالي نصف المساعدة المقترحة لمنطقة البحر منوسطية من برنامج المساعدة

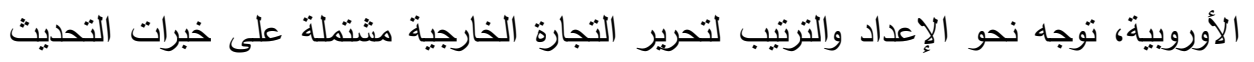

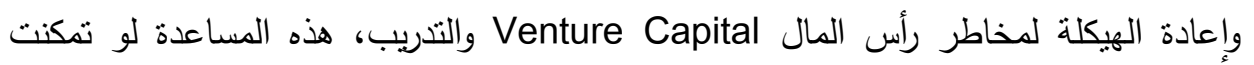

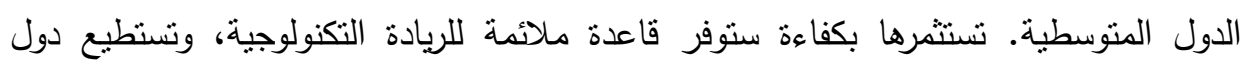

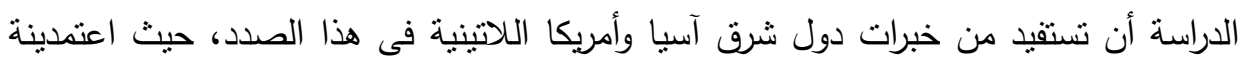

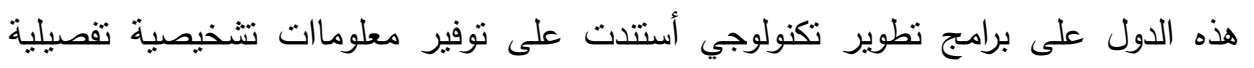

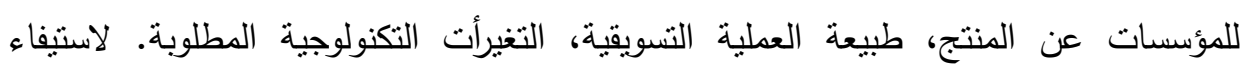
مواصفات الجودة والأسعار فى أسواق الصادرات.

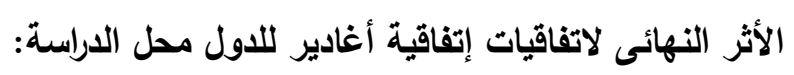

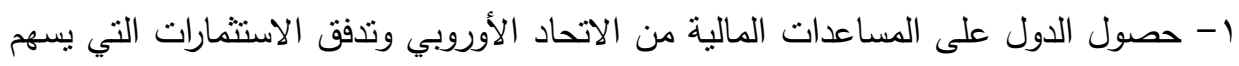

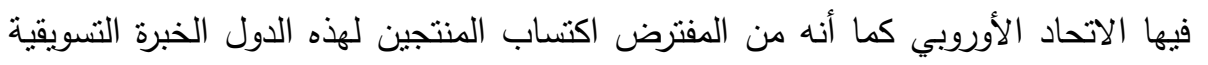
التي تمكنهم من زيادة صادراتهم للأسواق الأوروبية.

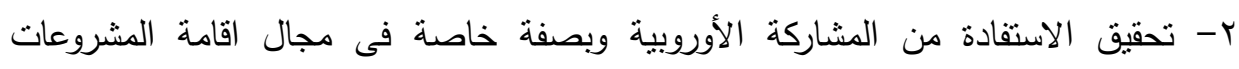

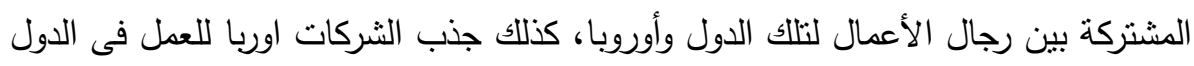
محل الدراسة أو عن طريق شركاء لانتاج سلع ليس للسوق المحلية فقط ولكن للتصدير

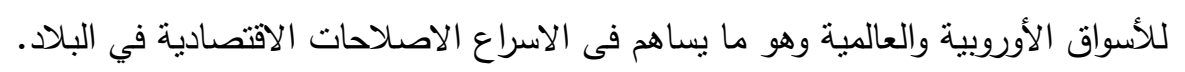

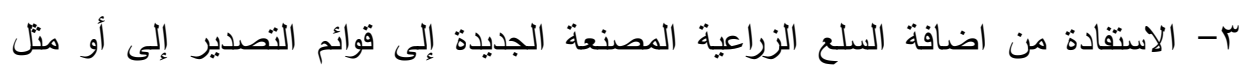
الزهور - الزمان ع - الاستفادة من تصدير الثروة السمكية إلى أوروبا مع تتمية تلك الثروة.

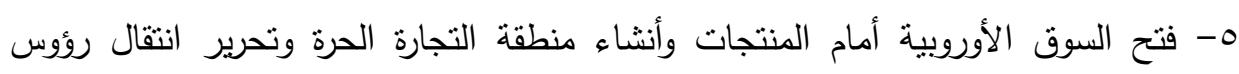

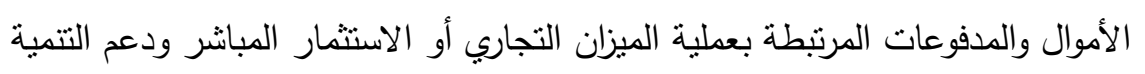


وارتباط زيادة الصادرات بمساهمة أوروبا فى تحديث التعليم والصناعة للقطاعين العام والخاص بحيث ترتفع قدراتهما التصديرية على الأمدين المتوسط والطويل.

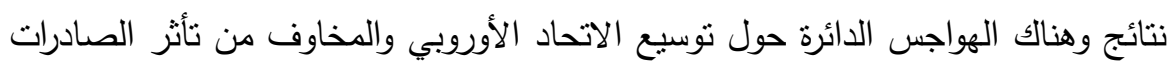

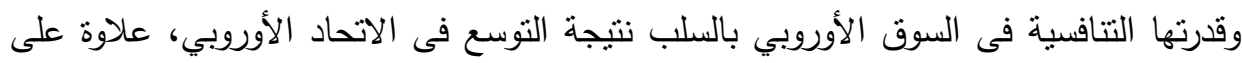

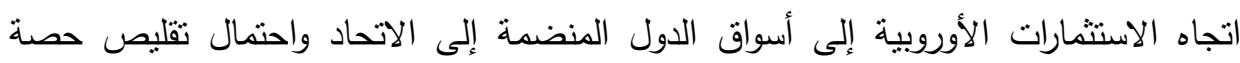

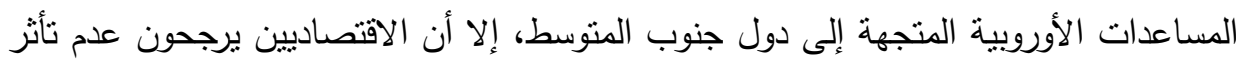

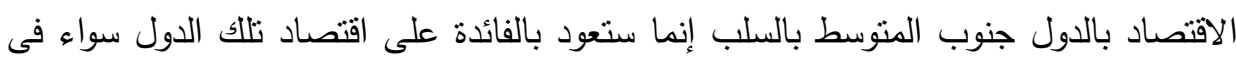
مجال فتح أسواق جديدة أمام صادرات دول وجنوب المتوسط، كما تتشير التوقعات بعدم نأثر بأن الاستثمارات بانضمام تلك الدول الجديدة، ويتوقف ذلك كله بالأساس على السياسات الاقتصادية

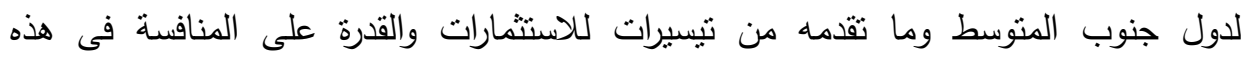
الأسواق.

نتائج هذا بالاضافة إلى العديد من السلبيات التي تثنوب البيئة الصناعية فى معظم الدول

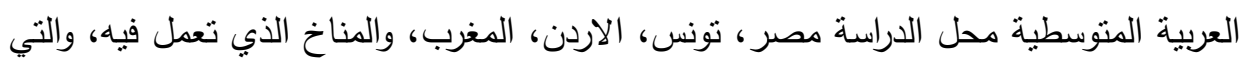

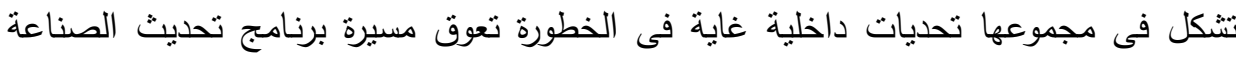
ويجب تداركها وهى تتمثل فى الآتي: 1- ضعف نظم الجودة. ץ- قصور دور البحث العلمي وتطوير التكنولوجيا والابتكار فى التطبيقات الصناعية. r- قصور التدريب. ع - ضعف التصنيع المحلي للمعدات الرأسمالية. 0- نطبيق البعد البيئي على الصناعة.

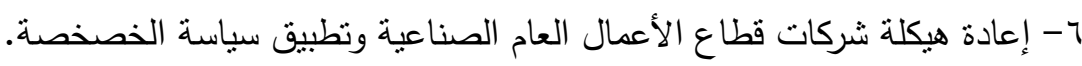
V- كثرة الأعباء الضريبية والجمركية التي يتحملها المنتج الوطني.

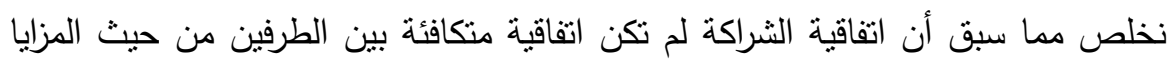

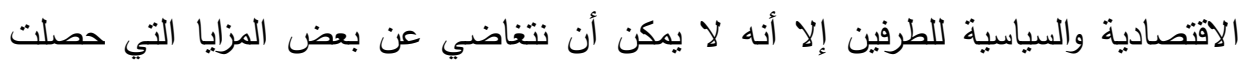

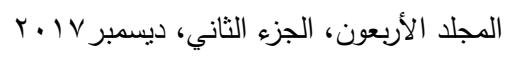


عليها الدول المتوسطية محل الدراسة من هذه الاتفاقية. وقد ثار جدل حول تقييم آثار الاتفاقية سواء الإيجابية أو السلبية، غير أن وجهة النظر الإيجابيات تغلب على النى السلبيات.

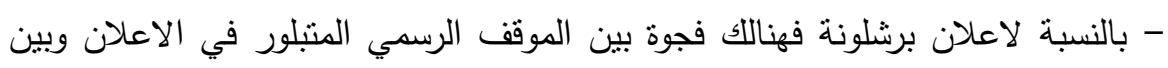

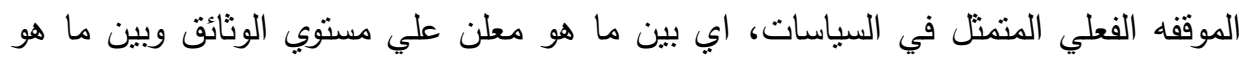
مطبق علي أرض الواقع.

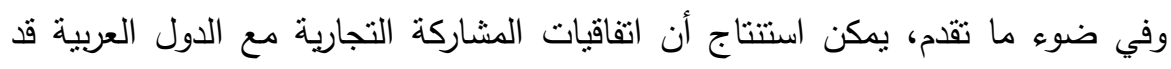

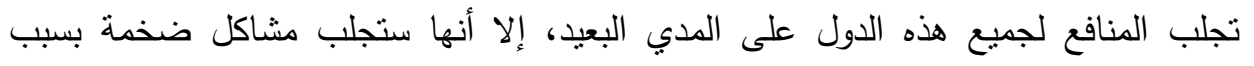

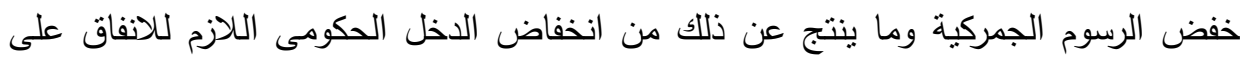
الخدمات الاجتماعية والاقتصادية. كذلك ستواجه الصناعات المحلية منافسة شرسة ونية ونير متكافئة مع الثركات الأوروبية مما يفرض تحديا يتعين مواجهته للتغلب على هذه المشاكل. إن تحقيق الأهداف المنشودة يعتمد على عوامل خارجية وعوامل أخرى داخلية تعتمد

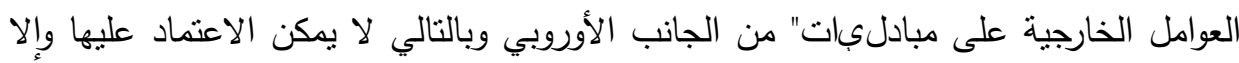

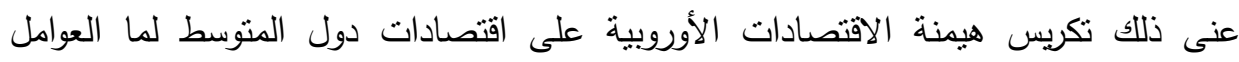
الداخلية فهي التي ينبغي الاعتماد عليها فسى دعائم الاقتصادات المتوسطة وتقويتها لتصدم أمام التهاد التغييرات القادمة من أوروبا بل وتحول مسارها نحو خدمة المصالح الوطنية.

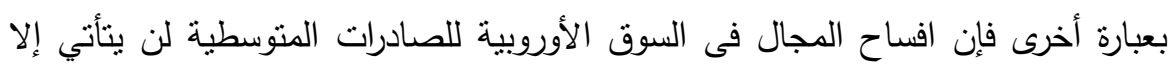
برفع قدرتها التنافسية القائمة على الكفاءة والجودة ولن يتحقق الحصول على مساعدات إنمائية، ليسوى بالتخطيط الجيد والإعداد لمشروعات ذات جدوى اقتصادية واجتماعية (أي مشروعات تدر أرباحا وترفع من مستويات التوظف والدخول) ففى تللك الحالة سوف يبادر الاتحاد الأوروبي

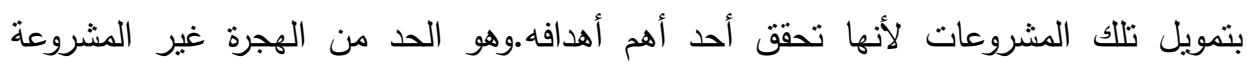
وتحقيق الاستقرار فى دول جنوب المتوسط وهي منطقة حيوية بالنسبة للأمن الأوروبي. 


\section{اللزوكياتص}

- - أن اكتساب الدول المتوسطية حصة مناسبة من السوق الأوربية ينطلب منها العمل على

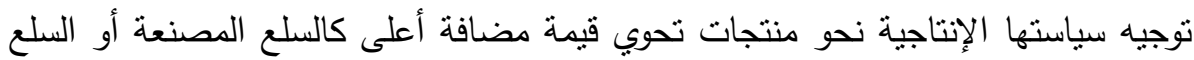

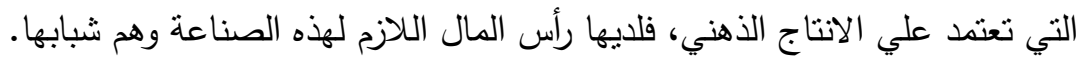

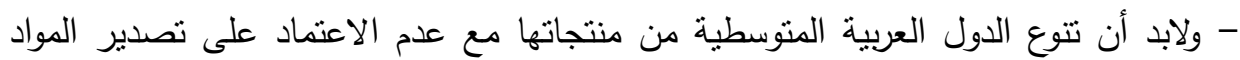

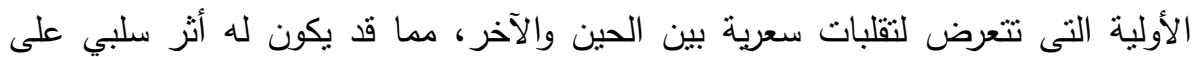

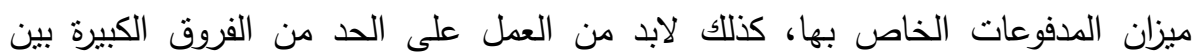
مؤشرات الأسعار الخاصة بها ومؤشرات الأسعار الأوروبية لأن مثل الفروق تمثل عوائق طبيعية للتصدير وتحد من قدرة منتجاتها على المنافسة. - ينبغي أيضاً السعي لإزالة القيود على المنتجات الزراعية التى تتمتع فيها أغلب تلك الدول بميزة نسبية عن مثيلاتها الأوروبية.

- وفى النهاية نتوقف جصة الدول المتوسطية على قدرة منتجاتها على منافسة منتجات دول

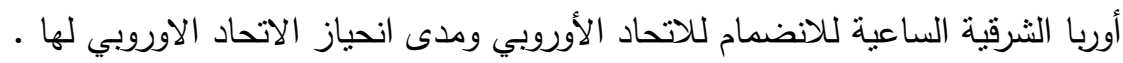

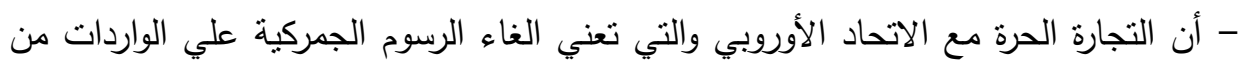

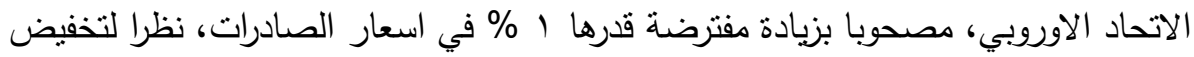

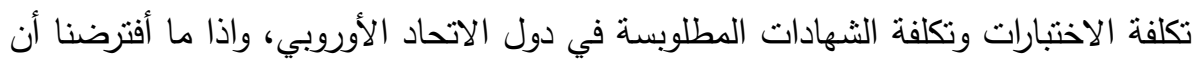
اتفاق المشاركة سيؤدي الي تخفيض التكاليف الادارية التي يتحملها التجار والتي تتمثل في

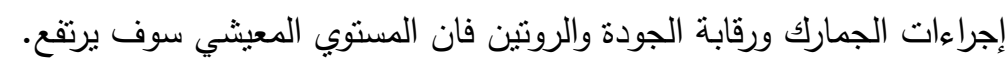

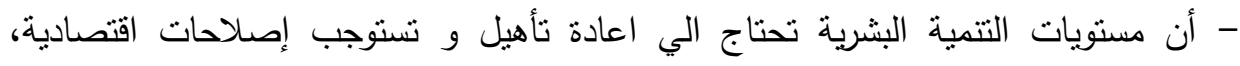
وسياسية واجتماعية مع ضرورة أن تتبع تللك الإصلاحات من الداخل وليس مسن الخارج،

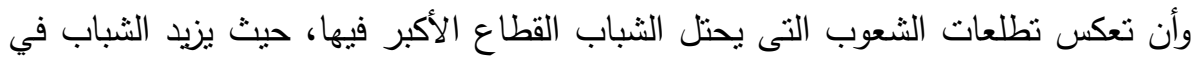

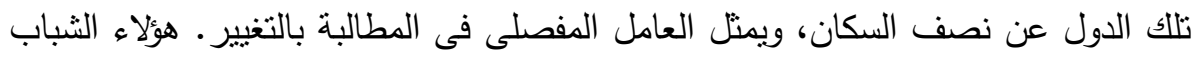

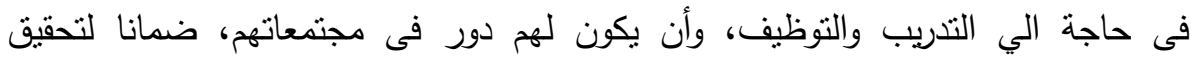

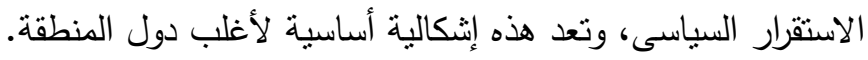


- على مستوى الصادرات العربية المتوسطية وخاصة الدول محل الدراسة بصفة عامة مطلوب تحسين أساليب التسويق والخدمات التسويقية من شحن وتعبئة وتغليفس وخفض الأعباء التي

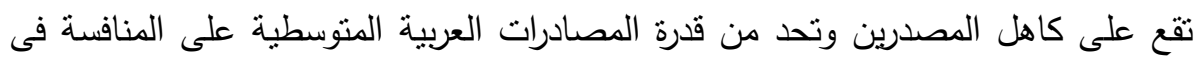
الأسواق الخارجية منل تكلفة الثحن والضرائب، وإنشاء شركات لضمان جودة المنتج في الدول العربية كما يجب أن تتدخل الدول المتوسطية العربية محل الدراسة لاستخدام نظم وأساليب تطوير صادراتها وفرض الثروط والضوابط على المنتج والمصدر من أجل ضمان شروط أفضل لصادراتها. - كان ينبغي أن تفوض الجامعة العربية عن الدول العربية كافة، كما يقوم الاتحاد الأوروبي بتمثيل الدول الأوروبية كافة.

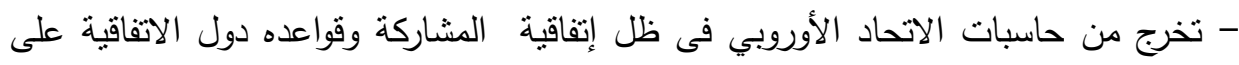
الرغم من أهميتها الحيوية للدول المتوسطية العربية، فى مقدمتها لبييا الظهير الجغرافي الغربي المباشر لمصر ، كما أن الحسابات يخرج منها الظهير.

\section{zent}

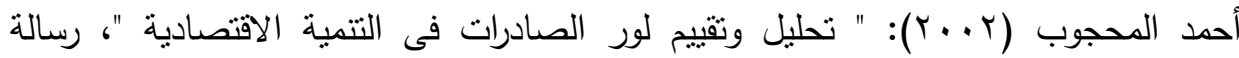

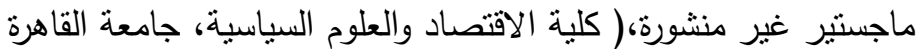

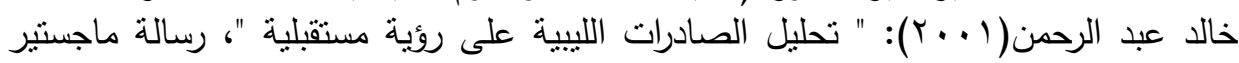

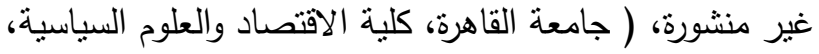

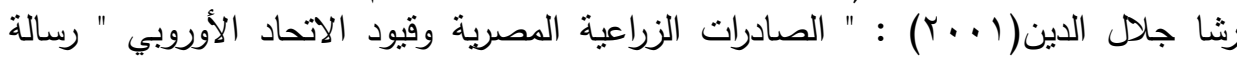

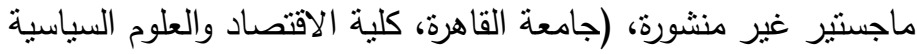

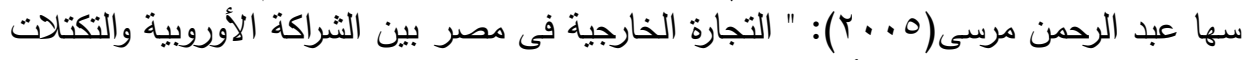
الاقتصادية الأفريقية"، رسالة ماجستير غير منشورة، (جامعة القاهرة، كلية

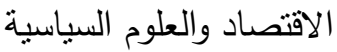
محمد سالمان طايع(997 (1): "الدائرة المتوسطية في السياسة السية الخارجية المصرية" رسالة ماجستير ، (جامعة القاهرة: كلية الاقتصاد والعلوم السياتية العاسية

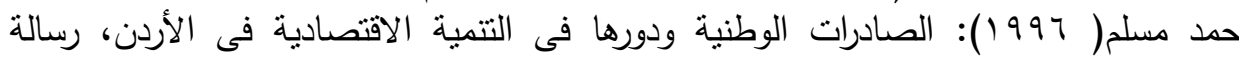
دكتوراه غير منشورة، (جامعة القاهرة، كلية الاقتصاد والعلوم السية التياسية 


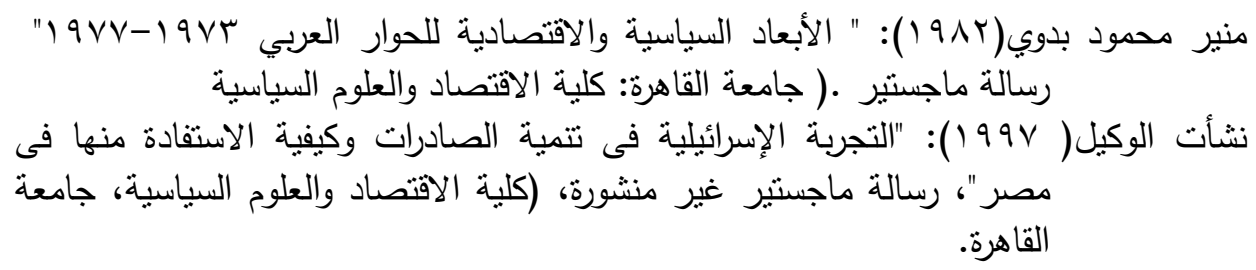

De Soto,Hernando, (1997): "Dead Capital and The Poor in Egypt", Distinguished Lecture Series 11, (A Publication of The Egyptian Center For Economic Studies

Dr Chourou, Bechir, (2006): * The Effect of the EMP and the ENP on Tunisia "workshop on "From Partnership to Neighbourhood...A Better Path for the Euro-Mediterranean Future (Konrad Adenauer stiftung \& Center of European study Cairo University Faculty of Econmic \& political Science..

Ei Khawaga Abla Mohamed (feb2005)," The Impact of American Economic Aid on Development and Growth in Egypt", Economic Studies, (cairo University, Faculty of Economic dipolitical Science), center for Economic \& . Financia Research \& studies, vol 33,).

Gala, Ahmed, (1996) "Egypt and the Partnership agreement with the EU: The road to maximum benefits", working paper, (Cairo, the Egyptian center for Economic Studies, no 9603;.

Ghoneim, Ahmed (Dec.2000): "Determinants of the Egyptian Export: Market Access to the European Union", Research Projects, Center for Economic \& Financial Research \& Studies.. Vol 10)

Hoekman, Bernard: "From Euro - Med Partnership to European Neighborhood: Deeper Integration and Economic Development " working paper, discussions at the Euro Mediterranean Economic Transition conference 2005 \& a Workshop on the European Neighborhood Policy organized by the Egyptian Center for Economic Studies, Cairo on May 3, 2005 (Development Research Group , World Bank and CEPR No. 103, )

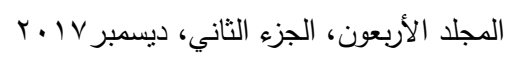


Kheir- El-Din, Hanaa \& Ghoneim, Ahmed F. (January 2007): "Trade Relations between the European Union and the Southern Mediterranean Countries". Discussion papers, no. 1. (Center for European Studies, Faculty of Economics \& political science, Cairo University,.

Kheir-EDin, Hanaa \& EISayed,,Hoda (1997): "Potential Impact of a free Trade Agreement with the EU on Egypt,s Textile Industry", Working Paper (The Egyptian center for Economic studies ECES, No 16 September

\title{
THE IMPACT OF AGHADEER CONVENTION ON EXTERNAL TRADE OF ITS MEMBERS EGYPT, JORDAN, MOROCCO, TUNIS
}

\author{
Mandour, A. F. ${ }^{(1)}$; Abu Elnil, N. A. A. ${ }^{(2)}$ \\ and Mohamed, Y. E. ${ }^{(3)}$
}

1) Faculty of Commerce, Ain Shams University 2) Faculty of Arts, Ain Shams University. 3) Faculty of Arts, Ain Shams University.

\begin{abstract}
This study aims to identify the reality and volume of trade between member countries of the Agadir Agreement and the European Union, develop a strategy to promote regional trade between member countries of the Agadir Agreement, bring more direct foreign trade investments between the member countries of the Agadir Agreement and the European Union, The study sample was composed of some member countries of the Agadir Agreement (Egypt, Jordan, Morocco, Tunisia). The researchers used two tools in the study: the first tool - The study of the main economic indicators of trade exchange with the countries of the Agadir Agreement and how to develop trade exchange to increase 398

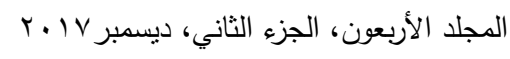




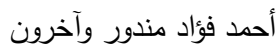

foreign investments and benefit from the requirements of this agreement. The second tool (analytical approach): - Study the reasons that lead to increase the trade exchange of countries of the Agadir Arab Mediterranean Free Trade Agreement, And the study reached some results, the most important of which: The Agadir Agreement allows the member states of the Convention the opportunity to receive grants, aid and experience, provided by the European side to qualify local industries to raise their competitiveness, The Agadir Agreement gives European exports to the Arab market advantages and customs exemptions in addition to its already existing competitive capabilities. The study also reached some recommendations, the most important of which are: the acquisition of the member states in the Agadir Agreement An appropriate share of the European market requires them to work to direct their production policy towards products containing higher value added goods manufactured or goods that depend on mental production, it has the capital needed for the industry as young people, and ultimately a share between member countries In the Agadir Agreement on the ability of their products to compete with Eastern European countries seeking to join the European Union and the bias of the European Union have products. ( Iman Ahmed Abdullah, 2013) 